IZA DP No. 10355

The Evolution of Multiple Jobholding in the U.S. Labor Market: The Complete Picture of Gross Worker Flows

Etienne Lalé

November 2016 


\title{
The Evolution of Multiple Jobholding in the U.S. Labor Market: The Complete Picture of Gross Worker Flows
}

\author{
Etienne Lalé \\ University of Bristol \\ and IZA
}

Discussion Paper No. 10355

November 2016

\author{
IZA \\ P.O. Box 7240 \\ 53072 Bonn \\ Germany \\ Phone: +49-228-3894-0 \\ Fax: +49-228-3894-180 \\ E-mail: iza@iza.org
}

Any opinions expressed here are those of the author(s) and not those of IZA. Research published in this series may include views on policy, but the institute itself takes no institutional policy positions. The IZA research network is committed to the IZA Guiding Principles of Research Integrity.

The Institute for the Study of Labor (IZA) in Bonn is a local and virtual international research center and a place of communication between science, politics and business. IZA is an independent nonprofit organization supported by Deutsche Post Foundation. The center is associated with the University of Bonn and offers a stimulating research environment through its international network, workshops and conferences, data service, project support, research visits and doctoral program. IZA engages in (i) original and internationally competitive research in all fields of labor economics, (ii) development of policy concepts, and (iii) dissemination of research results and concepts to the interested public.

IZA Discussion Papers often represent preliminary work and are circulated to encourage discussion. Citation of such a paper should account for its provisional character. A revised version may be available directly from the author. 


\section{ABSTRACT \\ The Evolution of Multiple Jobholding in the U.S. Labor Market: The Complete Picture of Gross Worker Flows ${ }^{*}$}

The U.S. labor market experienced a more than 20 percent reduction in the share of workers holding multiple jobs over the past 20 years. While this substantial trend is receiving increasing attention, the literature lacks a comprehensive picture of the gross worker flows that underlie the evolution of multiple jobholding. In this paper, first we construct new estimates of worker transitions into and out of multiple jobholding based on a Markov chain model that addresses several measurement issues. In particular, we show that timeaggregation bias cannot be ignored, as has been done in previous studies: workers typically hold a second job for a short period of time, which imparts a large bias in the estimates of transition probabilities. We go on to conduct a decomposition of the downward trend in multiple jobholding into the evolution of the underlying worker flows. This decomposition indicates that the trend is overwhelmingly explained by the dwindling propensity of full-time workers to take on a second job. We view the decrease in multiple jobholding as another manifestation of the changing labor supply behavior of U.S. workers observed during the past decades.

JEL Classification: E24, J21, J22, J60

Keywords: multiple jobholding, worker flows, trend decomposition

Corresponding author:

Etienne Lalé

Department of Economics

University of Bristol

Priory Road

Bristol BS8 1TU

United Kingdom

E-mail: etienne.lale@bristol.ac.uk

\footnotetext{
* An Excel spreadsheet with the data analyzed in this paper is available from the author's webpage. I am grateful to seminar participants at numerous institutions for useful comments on a predecessor of this paper. All errors are my own.
} 


\section{Introduction}

In the United States (U.S.) labor market, the fraction of workers who hold more than one job has declined by more than 20 percent over the past 20 years (Figure 1). This evolution may appear somewhat surprising, given that multiple jobholding during this period has been on the rise in countries like Canada and the United Kingdom, among others. ${ }^{1}$ Besides this comparison, a reason why the trend in multiple jobholding is receiving increasing attention relates to its ubiquitous role in the functioning of the U.S. labor market (e.g. Plewes and Stinson Jr [1991], Averett [2001], Kimmel and Smith Conway [2001]). Taking on a second job is a margin which individuals use mainly for the purpose of earning extra money, meeting regular expenses, paying off debt or saving for the future. ${ }^{2}$ Over the life cycle, it is estimated that no less than 50 percent of continuously-working (male) individuals hold a second job at some point (Paxson and Sicherman [1994]). The life-cycle component is especially visible in the higher propensity work a second job for economic reasons when individuals are between the age of 25 and 34, i.e. when households are being formed. Hence, multiple jobholding has far-reaching implications on decisions at the individual and the household level, such as job mobility decisions (Martinez-Granado [2005]), the choice to acquire new skills and change occupation (Panos et al. [2014]), household consumption and savings behavior, or the allocation of time to market work and housework (Stanczyk et al. [2016]).

A crucial first step to interpret the downward trend in the stock of multiple jobholders is to describe accurately the behavior of the gross worker flows that govern its evolution. As is well known, the U.S. labor market is highly dynamic and, consequently, a picture based on stocks says little about the size and changes of the underlying inflows and outflows. At a more substantive level, looking at worker flows allows to disentangle two (non-exclusive) explanations for the decline in multiple jobholding: that single jobholders have reduced their propensity to take on a second job, or that multiple jobholders have become more likely to give up their second job quickly. Our goal in this paper is to provide new estimates of the transition probabilities into and out of multiple jobholding, and to assess quantitatively their contribution to the decline observed over the last two decades.

The main results and contributions are as follows. First, in constructing the estimates of transition probabilities, we address a number of measurement issues and find that timeaggregation bias cannot be ignored when studying multiple jobholding. Time-aggregation bias refers to the fact that transition probabilities estimated using data at discrete time intervals miss some of the transitions that occur at a higher frequency. Multiple jobholding is especially prone to this bias because, as we document, it is a rather transitory state of employment. Thus,

\footnotetext{
${ }^{1}$ For Canada, Kimmel and Powell [1999] and Sussman [1998] document a steady, pronounced increase in multiple jobholding: they find that the fraction of workers with more than one job has increased two to three fold in 20 years. For the United Kingdom, Simic and Sethi [2002] report that the number of workers with multiple jobs grew more rapidly than employment since the mid-1980s. The authors note that examining the flows into and out of multiple jobholding would help to provide a comprehensive picture of this trend.

${ }^{2}$ It is common to refer to these motives as 'economic reasons' for holding a second job (see Martel [2000]). According to the May 2004 supplement of the Current Population Survey, economic reasons account for 63.7 percent of the stated reasons for multiple jobholding. There are also 'noneconomic reasons' for holding a second job. For instance 17.6 percent of respondents report that they hold more than one job mainly because they enjoy the work on the second job.
} 


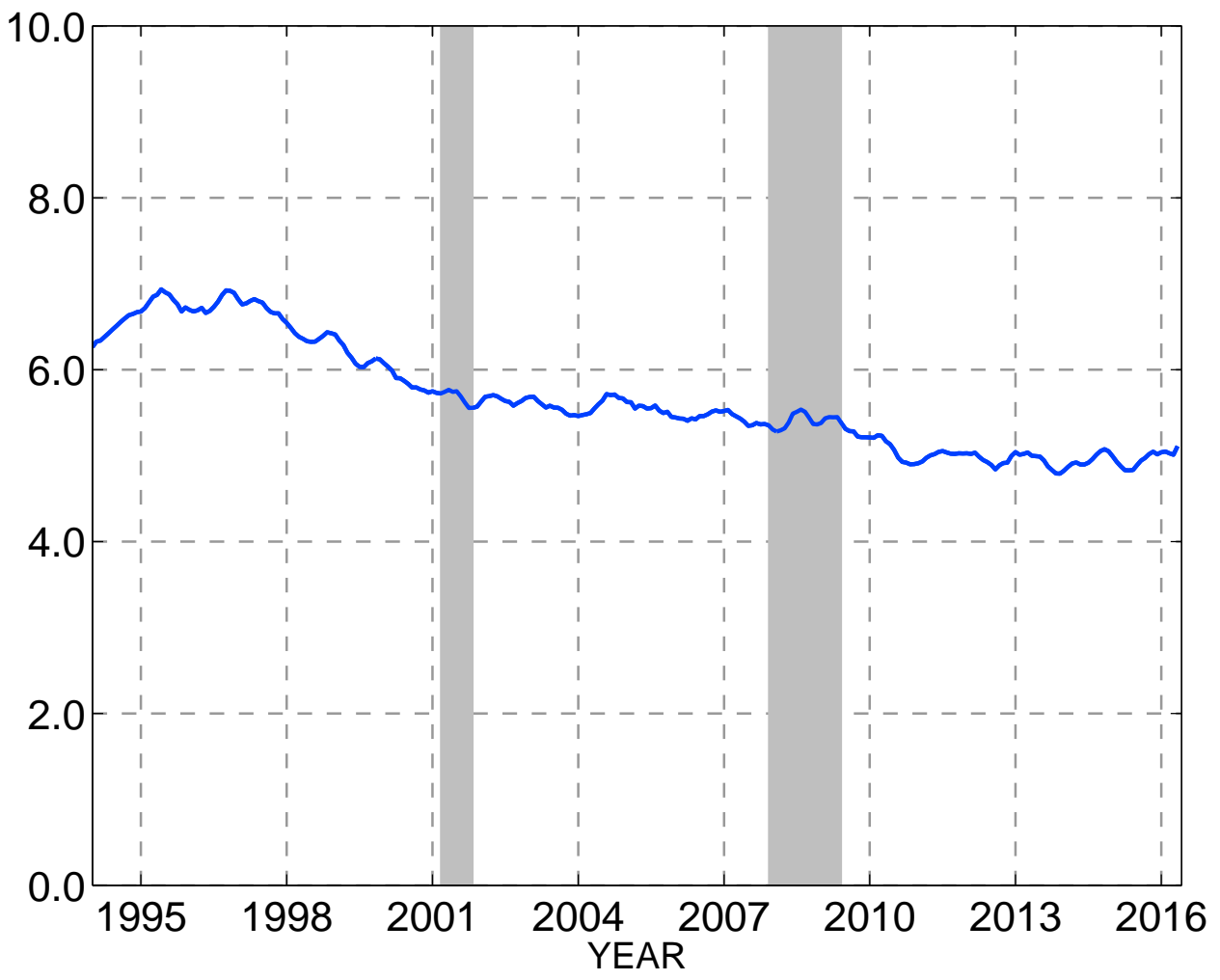

Figure 1: Multiple jobholding rate

NOTE: MA-smoothed time series cleared from seasonal variations and the effects of changes in demographics. Gray-shaded areas indicate NBER recession periods.

we argue that the time-aggregation adjusted data that we construct and make available with this paper are more reliable than existing estimates from the literature. Second, we implement a decomposition whereby the trend is partitioned into the changes driven by each transition probability in and out of multiple jobholding. This exercise reveals that the decrease in the probability that single jobholders take on a second job overwhelmingly explains the pattern depicted in Figure 1. That is, a trend in the opposite direction would be observed based on the behavior of the probability that multiple jobholders give up the second job, which decreased during the sample period. In sum, the evolution of the number of workers with multiple jobs veils substantial changes in the gross flows into and out of multiple jobholding.

As is common in the "ins and outs" literature (e.g. Fujita and Ramey [2009], Shimer [2012], Elsby et al. [2015]), we can estimate transition probabilities for individuals with different observable characteristics, but we cannot control for unobserved heterogeneity. Doing so is beyond the scope of our analysis, which documents the behavior of transition probabilities consistent with the observed number of workers with multiple jobs. Nevertheless, we think that unobserved heterogeneity could be key to explaining the changes in transition probabilities that we uncover. The decrease in the probability to give up the second job may indeed be driven by a so-called 'mover-stayer' phenomenon (Goodman [1961]) if workers with a shorter expected duration of multiple jobholding became less likely to take on second jobs. This points to changes in labor supply as the main driving force behind the trend shown in Figure 1. Following this line of interpretation, in Section 5 we complement the results by reviewing several empirical 
findings consistent with a labor-supply explanation of the decline in multiple jobholding. ${ }^{3}$

This paper is primarily related to a literature that seeks to understand the evolution of multiple jobholding across space and time, possibly at different time frequencies. As previously mentioned, this research is growing because of the need to understand the trend in multiple jobholding, and more generally the evolution of alternative work arrangements (see e.g. Abraham et al. [2015] and Katz and Krueger [2016]). Hirsch et al. [2016b] document a number of geographic differences in multiple jobholding, and they review a range of explanatory factors. Amuedo-Dorantes and Kimmel [2009] and Hirsch et al. [2016a] study the relationship between multiple jobholding and the business cycle. We corroborate their finding, that this relationship is very weak. This said, our focus is on the long-run evolution of multiple jobholding, not its short-run variations. An antecedent of this paper is the study by Lalé [2015]. Our results correct the estimates presented in that study, which were biased by the measurement issues discussed in Section 3. ${ }^{4}$ In addition, we quantify the contribution of changes in transition probabilities to the trend in multiple jobholding using a variance decomposition, whereas in Lalé [2015] this relationship is analyzed only qualitatively.

Our analysis contributes also to research on the dynamics of labor markets based on workerlevel data. This research has identified several measurement issues that arise with these data. We adapt the methods recently proposed by Shimer [2012] and Elsby et al. [2015] to address margin-error problems and time-aggregation bias, which have long been recognized in the literature. $^{5}$ Another issue which has come under scrutiny lately is 'rotation group bias'; see Krueger et al. [2016]. This bias refers to systematic differences in the outcomes measured among different interview groups of a survey with a rotational structure, such as the Current Population Survey. In fact, Hirsch and Winters [2016] find that rotation group bias alters the measurement of multiple jobholding in that survey. They also document that it contributes to the downward trend observed during the past 20 years. In Appendix B.2, we investigate the implications of rotation group bias for our results and show that it has little impact on the trends in transition probabilities. Finally, in research on the dynamics of labor markets, it is common to study fluctuations in stocks at different frequencies through the lens of a variance decomposition. Like Barnichon and Figura [2015] or Borowczyk-Martins and Lalé [2016], we use a flexible decomposition to analyze the long-run behavior of the labor market.

Last, this paper adds to a flurry of recent findings about changes in labor supply behaviors, which are summarized in Section 5 of the paper. At this point, we find it worth underlining three features of these changes. First, they may be specific to the United States, or at least they appear to be more pronounced in this country. For instance, as noted in the opening

\footnotetext{
${ }^{3}$ One potential explanation not discussed in Section 5 builds on the idea of measurement error, and attributes the downward trend to new forms of multiple jobholding which standard survey items fail to capture. In particular, recent analyses by Abraham et al. [2015] and Katz and Krueger [2016] emphasize that employment in the 'online gig economy' is not well measured by labor force surveys. This problem may lead to a downward bias in the estimates of the number of multiple jobholders at the end of the sample period, but it cannot explain the trend over a twenty-year period.

${ }^{4}$ The study of multiple jobholding by Zhao [2016] also contains estimates of transition probabilities that do not control for margin error and time aggregation. It is likely that these estimates suffer from the same biases.

${ }^{5}$ Poterba and Summers [1986] analyzed the margin-error problem presented in Subsection 3.1. As for time aggregation bias, to our knowledge the issue is known at least since the works of Kaitz [1970] and Perry [1972].
} 
paragraph, the decline of multiple jobholding has not been observed in some other countries with a flexible labor market (Sussman [1998], Simic and Sethi [2002]). Second, these changes seem to contradict a previous trend in the U.S. towards supplying more hours of work. Indeed, Kuhn and Lozano [2008] report a lengthening of the workweek of full-time (male) workers during the 1980s. This trend was not driven by a decrease in multiple jobholding, which was actually on an upward course during this period (see Stinson Jr [1990] and Kimmel and Powell [1999]). ${ }^{6}$ Third, in previous decades the shifts away from the labor market were mostly concentrated on individuals with lower-than-average education and market opportunities. By contrast, during the last 20 years it seems that these shifts have occurred among individuals from the higher half of the income distribution (Hall [2016], Hall and Petrosky-Nadeau [2016]). This is relevant for multiple jobholding because the latter is far more prevalent among more educated individuals than among workers in low-skill, low-wage occupations.

The rest of the paper is organized as follows. Section 2 presents the data, definitions and preliminary facts about the evolution of multiple jobholding in the United States. Section 3 describes the statistical framework used to construct gross labor market flows, and how these are affected by several measurement issues. In Section 4, we lay out a decomposition of the trend into the contribution of the different flows into and out of multiple jobholding. Section 5 takes stock of the results by relating them to a number of labor market changes recently documented in the literature. The last part of Section 5 concludes.

\section{Data, definitions and preliminary facts}

This section presents the data, definitions of the main concepts used in the analysis, and a set of preliminary facts about multiple jobholding.

\subsection{Data source}

The data we use come from the monthly files of the Current Population Survey (CPS). The CPS is a survey of households administered by the U.S. Census Bureau under the auspices of the U.S. Bureau of Labor Statistics (BLS). This survey has informed the majority of studies on worker flows in the U.S. labor market, and thus it is a natural choice for our purposes. Since January 1994, the CPS has been collecting information which allow the identification of multiple jobholders (details follow). ${ }^{7}$

CPS respondents are interviewed for four consecutive months, are rotated out of the survey for eight months, and are included in the survey again for four consecutive months. As a result, in each monthly file of the CPS, about three-quarters of respondents were already in the sample in the previous month. In Section 3, we use this feature to match individuals from the non-outgoing groups so as to measure gross worker flows over a time horizon of one month. ${ }^{8}$

\footnotetext{
${ }^{6}$ The evidence for the U.S. during the 1980s comes from the May supplements of the CPS. These supplements provide valuable information about multiple jobholding, but only as discrete snapshots.

${ }^{7}$ The CPS underwent a major redesign in January 1994 (Cohany et al. [1994]). Prior to 1994, the regular survey items of the CPS did not include questions on multiple jobholding.

${ }^{8}$ We use household and personal identifiers combined with an age/race/sex filter to match CPS respondents.
} 


\subsection{Definitions}

A key operational definition in this paper is that of a multiple jobholder. We follows the BLS and count as multiple jobholders those individuals who hold more than one job during the reference week and who usually receive a wage or salary from the primary job. We also adopt the BLS definition of the primary job, which is the job with the greatest number of hours worked during the reference week of the survey. The CPS collects information on hours for up to two jobs at each interview. This allows to identify the primary job of the vast majority of multiple jobholders, who hold 'only' two jobs. ${ }^{9}$ In the absence of further information, we use the same approach for individuals who hold more than two jobs.

Another important definition of the analysis is that of part-time employment. In labor market statistics, whether a job is considered part-time or full-time depends on the number of hours usually worked at this job. We use a threshold of 35 usual hours to distinguish between part-time and full-time jobs. This threshold is standard in U.S. statistics and it does not drive our results. The results based on a different cutoff for part-time work are available upon request.

\subsection{Preliminary facts}

In this section, we lay out several preliminary facts about multiple jobholding. We start with the average characteristics over the sample period presented in columns 1 and 2 of Table 1.

The first noticeable fact is that the fraction of employed workers who hold more than one job (column 1) is consistently between 5 and 6 percent for most of the socio-demographic groups studied in the table. The main exception relates to education, which we discuss momentarily. This uniformity is remarkable because, as shown in column 2, there is a significant degree of variation across groups regarding the fraction of multiple jobholders with a part-time primary job. For example, women are twice more likely than men to hold a part-time primary job when they work multiple jobs (38.3 vs. 17.5 percent). That said, the second salient fact in Table 1 is that almost three quarters (72.3 percent) of multiple jobholders are working full-time at their primary job. In this respect, the view that multiple jobholders are merely combining two part-time jobs to make a full-time income is empirically misplaced. Third, as just noted, the rates of multiple jobholding differ markedly across individuals with different education levels. In particular, multiple jobholding increases with educational attainment. This is in line with earlier studies on this topic. Amirault [1997] and Lalé [2015] report additional figures which dovetail with the correlation between multiple jobholding and higher education. For instance, multiple jobholding is more common among workers whose primary job is in a managerial or a professional occupation, and less prevalent among workers in the mining, construction or manufacturing industry.

Next, we remark on the changes in multiple jobholding reported in the columns 3 to 5 of Table 1. From 1995 to 2015, the multiple jobholding rate decreased by 23.7 percent on average

\footnotetext{
${ }^{9}$ We find that, on average over the sample period, 92 percent of multiple jobholders do not hold more than two jobs. Among workers who hold three or more jobs, 65 percent report working full-time on one of the two jobs for which the information is available. For those individuals, it seems reasonable to assume that one of these two jobs is the primary job.
} 
Table 1: Multiple jobholding, overall and by socio-demographic groups

\begin{tabular}{|c|c|c|c|c|c|}
\hline & \multicolumn{2}{|c|}{ Average } & \multicolumn{3}{|c|}{ Change in multiple jobholding } \\
\hline & \multirow{3}{*}{$\begin{array}{l}\text { Multiple } \\
\text { jobholding } \\
(1)\end{array}$} & \multirow{3}{*}{$\begin{array}{c}\text { Part-time } \\
\text { on } 1^{\text {st }} \text { job } \\
(2)\end{array}$} & \multicolumn{2}{|c|}{ Average in: } & \multirow{3}{*}{$\begin{array}{c}\triangle(\%) \\
(5)\end{array}$} \\
\hline & & & 1995 & 2015 & \\
\hline & & & $(3)$ & $(4)$ & \\
\hline All & 5.71 & 27.7 & 6.72 & 5.13 & -23.7 \\
\hline \multicolumn{6}{|l|}{ (a) Gender } \\
\hline Men & 5.49 & 17.5 & 6.75 & 4.75 & -29.6 \\
\hline Women & 5.96 & 38.3 & 6.68 & 5.55 & -17.0 \\
\hline \multicolumn{6}{|l|}{ (b) Age } \\
\hline 16 to 24 years & 5.55 & 54.3 & 6.46 & 5.45 & -15.6 \\
\hline 25 to 54 years & 5.81 & 22.6 & 6.94 & 5.11 & -26.4 \\
\hline 55 to 64 years & 5.28 & 27.6 & 5.27 & 4.96 & -5.86 \\
\hline \multicolumn{6}{|l|}{ (c) Education } \\
\hline Less than high-school & 2.82 & 40.0 & 3.46 & 2.52 & -27.2 \\
\hline High-school graduates & 4.47 & 24.8 & 5.38 & 3.93 & -26.9 \\
\hline Some college & 6.61 & 31.9 & 7.91 & 5.89 & -25.5 \\
\hline College or higher education & 7.06 & 25.1 & 8.57 & 5.98 & -30.2 \\
\hline \multicolumn{6}{|l|}{ (d) Marital status } \\
\hline Married & 5.52 & 23.7 & 6.55 & 4.89 & -25.4 \\
\hline Widowed; divorced; separated & 6.47 & 22.1 & 7.33 & 5.67 & -22.7 \\
\hline Single & 5.71 & 38.5 & 6.79 & 5.30 & -21.9 \\
\hline
\end{tabular}

NOTE: The entries in columns 1 to 4 of the table are reported in percentage points. Column 5 of the table displays the relative change in percent of the multiple jobholding rate between 1995 and 2015, which is reported for these two years in columns 3 and 4 of the table, respectively.

across workers. ${ }^{10}$ The decline is broad-based; for example, in spite of differences in the rates of multiple jobholding, all educational groups experienced a reduction of the same magnitude in relative terms. A direct implication is that the trend in the aggregate is not explained by a compositional change towards those groups of workers who are less likely to hold several jobs - at least not for the socio-demographic characteristics studied in Table $1 .{ }^{11}$ Meanwhile, the second fact highlighted in columns 3 to 5 is that the downward trend was more pronounced among male than among female workers: a 29.6 vs. a 17.0 percent decrease. The next paragraph provides additional observations about this discrepancy. Finally, we note that the trend is also different between prime-age workers on the one hand and younger and older workers on the other hand. However, the latter two categories are less relevant to understand the evolution of multiple jobholding because they account for a relatively small share of employment.

To complement Table 1, Figure 2 shows the multiple jobholding rates separately for men and women. In the remainder of the analysis, instead of working only with the aggregated data, we will often present the results for both male and female workers. We focus on this

\footnotetext{
${ }^{10}$ The multiple jobholding rate is the number of workers who hold more than one job divided by the total number of employed workers (Section 4).

${ }^{11}$ To clear the data from the effects of changing demographics, we hold constant over the sample period the gender and education characteristics of employed workers to compute the multiple jobholding rate in Figure 1. The unadjusted time series is very similar to that displayed in Figure 1 (see Figure 1 in Lalé [2015]).
} 
partition because of the heterogeneity with respect to part-time/full-time work and the slightly different timing of the decline in multiple jobholding between male and female workers. This difference can be seen by scrutinizing the time series in Figure 2. For women, it is visible that the multiple jobholding rate plateaued in the 2000s and resumed its decline only during or after the Great Recession. For men on the other hand, the decline seems to have been uninterrupted since 1995. In the next section, we document the behavior of the gross worker flows that drive these changes in the stocks of multiple jobholders.

(a) Men

(b) Women

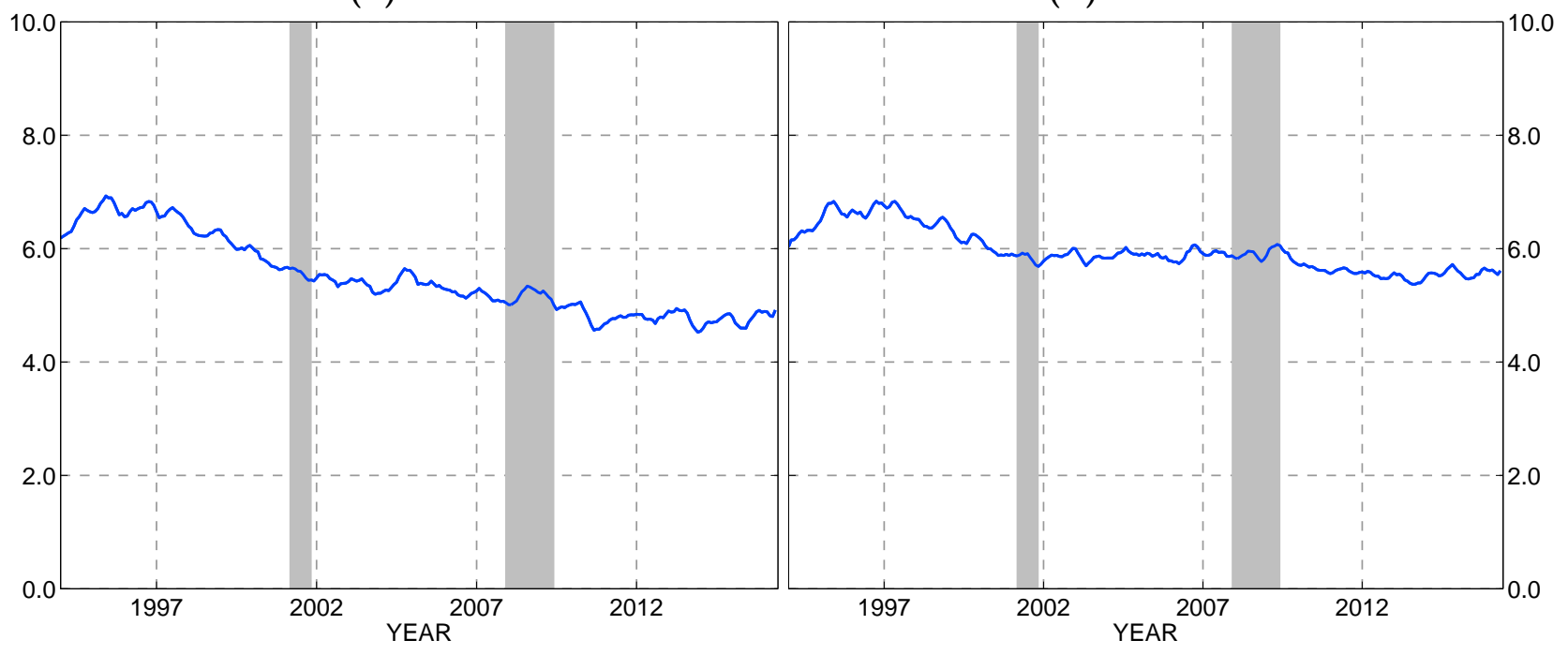

Figure 2: Multiple jobholding rate: Men and women NOTE: MA-smoothed time series cleared from seasonal variations. Gray-shaded areas indicate NBER recession periods.

\section{The ins and outs of multiple jobholding}

This section introduces our framework to measure transitions into and out of multiple jobholding, and presents our estimates of transition probabilities.

\subsection{Empirical approach}

We resort to a stock-flow framework to document transitions into and out of multiple jobholding. In each period $t$, individuals are classified into one of the following states: multiple jobholding with a full-time primary job $\left(F_{M}\right)$, multiple jobholding with a part-time primary job $\left(P_{M}\right)$, single jobholding with a full-time job $\left(F_{S}\right)$, single jobholding with a part-time job $\left(P_{S}\right)$, and nonemployment $(N)$. We let the vector $\boldsymbol{\ell}_{t}$ contain the number of individuals (stocks) in each of these states:

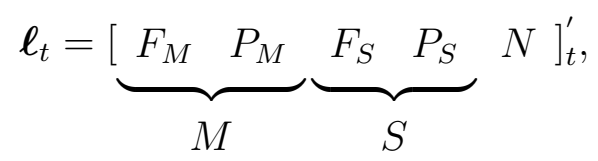

where $M=F_{M}+P_{M}$ (resp. $S=F_{S}+P_{S}$ ) is the number of multiple jobholders (resp. single jobholders) in period $t$. As is standard, the evolution of $\boldsymbol{\ell}_{t}$ is described by means of a discrete- 
time, first-order Markov chain:

$$
\ell_{t}=\boldsymbol{X}_{t} \ell_{t-1}
$$

In this equation, $\boldsymbol{X}_{t}$ is the stochastic matrix of transition probabilities $p(i \rightarrow j)$ across labor market states $i$ and $j$. Each of these transition probabilities is measured by the gross flow of workers from state $i$ to state $j$ at time $t$ divided by the stock of worker in state $i$ at time $t-1$.

We implement several adjustments based on the Markov chain structure of this framework. ${ }^{12}$ First, we perform a so-called margin-error adjustment of the transition probabilities (Poterba and Summers [1986], Elsby et al. [2015]). Briefly, this adjustment reconciles the changes in stocks predicted by the Markov chain with the actual changes in stocks between two consecutive periods. Second, we correct transition probabilities to account for time-aggregation bias (Shimer [2012]). The mechanisms underlying this adjustment are discussed in the next subsection. We refer the reader to Appendix A for a formal presentation of the adjustment procedures. The role of margin error is documented in Appendix B.1.

\subsection{Time-aggregation bias}

Time-aggregation bias refers to the discrepancy between the transition probabilities measured at discrete intervals and the underlying continuous process which they seek to measure. Specifically, the competing risks structure of the process implies that the discrete-time (monthly) probabilities miss some of the transitions that occur at a higher frequency. We apply Shimer [2012]'s continuous-time correction to address this bias.

Table 2: Transition into and out of multiple jobholding: Time-aggregation bias

\begin{tabular}{|c|c|c|c|c|c|c|}
\hline & \multicolumn{3}{|c|}{ Average } & \multicolumn{3}{|c|}{$\triangle(\%)$ from 1995 to 2015} \\
\hline & $\begin{array}{l}\text { Unadjusted } \\
\text { (1) }\end{array}$ & $\begin{array}{c}\text { Adjusted } \\
(2)\end{array}$ & $\begin{array}{c}\triangle(\%) \\
(3)\end{array}$ & $\begin{array}{c}\text { Unadjusted } \\
(4)\end{array}$ & $\begin{array}{l}\text { Adjusted } \\
(5)\end{array}$ & $\begin{array}{c}\triangle(\%) \\
\quad(6)\end{array}$ \\
\hline \multicolumn{7}{|l|}{ (a) Inflows } \\
\hline$F_{S} \rightarrow M$ & 1.57 & 1.87 & 18.9 & -0.60 & -0.74 & 23.7 \\
\hline$P_{S} \rightarrow M$ & 2.68 & 3.61 & 34.8 & -0.80 & -1.15 & 43.1 \\
\hline$N \rightarrow M$ & 0.24 & 0.16 & -32.3 & -0.09 & -0.06 & -32.9 \\
\hline \multicolumn{7}{|l|}{ (b) Outflows } \\
\hline$F_{M} \rightarrow S$ & 28.9 & 29.9 & 3.51 & -1.51 & -1.59 & 4.83 \\
\hline$P_{M} \rightarrow S$ & 29.9 & 34.1 & 14.2 & -2.87 & -3.59 & 24.8 \\
\hline$M \rightarrow N$ & 3.72 & 2.37 & -36.2 & -0.77 & -0.54 & -29.2 \\
\hline
\end{tabular}

NOTE: Columns 1 and 2 of the table display the average of transition probabilities in percentage points. Columns 4 and 5 display the relative change in percent of the corresponding transition probability between 1995 and 2015. Column 3 (resp. 6) reports the percentage change from the unadjusted to the adjusted figures displayed in columns 1 and 2 (resp. 4 and 5) of the table.

Table 2 describes the impact of time-aggregation bias on the levels and trends of the inflows and outflows of multiple jobholding. Beginning with the levels of transition probabilities (columns 1 to 3 ), the effect of time aggregation goes in the expected direction. On the one

\footnotetext{
${ }^{12}$ Prior to making these adjustments, we filter out potential outliers and remove systematic seasonal variations using the Census Bureau's X-13ARIMA-SEATS program (https://www. census.gov/srd/www/x13as/).
} 
hand, transitions between nonemployment $(N)$ and multiple jobholding $(M)$ are overestimated in the unadjusted data, because some of these transitions involve an intervening spell of single jobholding. On the other hand, transitions between single $\left(F_{S}\right.$ or $\left.P_{S}\right)$ and multiple jobholding are underestimated in the unadjusted data due to the substantial turnover between these labor market states. This is true especially for single jobholding with a part-time job $\left(P_{S}\right)$ : for instance, the probability to take on a second job in that state is 34.8 percent higher after accounting for time-aggregation bias. ${ }^{13}$

Next, in columns 4 to 6 of Table 2, we see that time aggregation imparts a substantial bias in the evolution of transition probabilities over the sample period. That is, the change in the probability to take on a second job for those with a single full-time job $\left(F_{S}\right)$ is downward-biased by 23.7 percent. For those with a single part-time job $\left(P_{S}\right)$, this figure rises to 43.1 percent. The bias is also non-negligible for multiple jobholders who work part-time on their primary job: the decrease in the probability to return to single jobholding is 24.8 percent higher in the adjusted data. In addition, as we explain in Appendix B.1, the data that do not control for margin error miss the downward trend in the probability to return to single jobholding. A provisional conclusion is that previous estimates of transition probabilities, such as those presented in Lalé [2015], give only an incomplete picture of the evolution of multiple jobholding.

\subsection{The complete picture of gross workers flows}

Table 3 describes the dynamics of multiple jobholding through its interaction with other labor market states. Figures 3 and 4 complement the table by displaying, respectively, the transition probabilities in and out of multiple jobholding. There are two displayed time series in each plot, except for the plots at the bottom showing a transition to or from nonemployment $(N)$. For instance, in Figure 3 for single jobholding with a full-time job $\left(F_{S}\right)$, the solid line denotes the probability to take on a second job (i.e. move to either $F_{M}$ or $P_{M}$ ) while the dashed line is the probability to take on a second job and hold a full-time primary job $\left(F_{M}\right)$. Clearly, in each plot, the transition probability indicated by the dashed line is the main component of the transition probability indicated by the solid line.

\section{Long-run averages}

Each panel of Table 3 reports the averages of inflow and outflow transition probabilities and their evolution over the sample period. ${ }^{14}$ The bottom row of each panel displays the sum of the inflow (resp. outflow) transition probabilities whose states of origin (resp. destination) exclude multiple jobholding. A first striking result is that multiple jobholding is a rather transitory state. When looking at individuals with a full-time primary job $\left(F_{M}\right)$, about one third (34.8

\footnotetext{
${ }^{13}$ To give an order of magnitude, we computed the time-aggregation bias of the so-called separation rate (transitions from employment to unemployment) and the job-finding rate (transitions from unemployment to employment) over the same period. The bias we obtained were 31.5 percent and 24.1 percent, respectively. The impact of time aggregation on the fluctuations of unemployment has been an actively researched issue in recent years (e.g. Fujita and Ramey [2009], Shimer [2012]).

${ }^{14} q(i \rightarrow j)$ denotes the inflow transition probability from state $i$ to $j$. It is the ratio of the gross flow from state $i$ to $j$ between time $t-1$ and $t$ over the stock of workers in state $j$ at time $t$. The outflow transition probabilities are the elements of the Markov transition matrix in equation (2).
} 
percent) were in a different state in the previous month and a similarly large share leaves in the following month (30.4 percent). The figures are slightly higher for multiple jobholders who work part-time on the primary job $\left(P_{M}\right)$. Second, a non-negligible share of workers change status with respect to their primary job on moving into or out of multiple jobholding. This holds true especially for multiple jobholders with a part-time primary job during the reference week $\left(P_{M}\right)$ : the probability that they hold a single full-time job $\left(F_{S}\right)$ in the previous month or during the month that follows is between 6 and 7 percent. Third, transitions between multiple jobholding and nonemployment $(N)$ are negligible. This feature dovetails well with our choice of lumping together individuals in unemployment and those out of the labor force.

Table 3: Inflow and outflow transition probabilities: Sample averages

\begin{tabular}{|c|c|c|c|c|c|}
\hline \multicolumn{6}{|c|}{ (a) Full-time on the $1^{s t}$ job $\left(F_{M}\right)$} \\
\hline \multicolumn{3}{|c|}{ Inflows } & \multicolumn{3}{|c|}{ Outflows } \\
\hline & $\begin{array}{c}\text { Average } \\
\text { (1a) }\end{array}$ & $\begin{array}{c}\triangle(\%) \text { from } \\
1995 \text { to } 2015 \\
(2 \mathrm{a})\end{array}$ & & $\begin{array}{c}\text { Average } \\
(3 \mathrm{a})\end{array}$ & $\begin{array}{c}\triangle(\%) \text { from } \\
1995 \text { to } 2015 \\
(4 \mathrm{a})\end{array}$ \\
\hline$q\left(P_{M} \rightarrow F_{M}\right)$ & 6.21 & 19.9 & $p\left(F_{M} \rightarrow P_{M}\right)$ & 6.07 & 28.6 \\
\hline$q\left(F_{S} \rightarrow F_{M}\right)$ & 32.6 & -6.25 & $p\left(F_{M} \rightarrow F_{S}\right)$ & 28.9 & -5.90 \\
\hline$q\left(P_{S} \rightarrow F_{M}\right)$ & 1.60 & 12.1 & $p\left(F_{M} \rightarrow P_{S}\right)$ & 1.01 & 12.7 \\
\hline$q\left(N \rightarrow F_{M}\right)$ & 0.63 & 62.7 & $p\left(F_{M} \rightarrow N\right)$ & 0.56 & -4.88 \\
\hline$\sum_{i \neq M} q\left(i \rightarrow F_{M}\right)$ & 34.8 & -4.27 & $\sum_{j \neq M} p\left(F_{M} \rightarrow j\right)$ & 30.4 & -5.20 \\
\hline
\end{tabular}

(b) Part-time on the $1^{\text {st }}$ job $\left(P_{M}\right)$

Inflows

\begin{tabular}{|c|c|c|c|c|c|}
\hline & $\begin{array}{c}\text { Average } \\
(1 b)\end{array}$ & $\begin{array}{c}\triangle(\%) \text { from } \\
1995 \text { to } 2015 \\
(2 \mathrm{~b})\end{array}$ & & $\begin{array}{c}\text { Average } \\
(3 \mathrm{~b})\end{array}$ & $\begin{array}{c}\triangle(\%) \text { from } \\
1995 \text { to } 2015 \\
(4 b)\end{array}$ \\
\hline$q\left(F_{M} \rightarrow P_{M}\right)$ & 15.9 & -0.76 & $p\left(P_{M} \rightarrow F_{M}\right)$ & 16.3 & -7.08 \\
\hline$q\left(F_{S} \rightarrow P_{M}\right)$ & 6.27 & 21.3 & $p\left(P_{M} \rightarrow F_{S}\right)$ & 7.09 & 33.8 \\
\hline$q\left(P_{S} \rightarrow P_{M}\right)$ & 32.9 & -21.0 & $p\left(P_{M} \rightarrow P_{S}\right)$ & 27.1 & -19.3 \\
\hline$q\left(N \rightarrow P_{M}\right)$ & 2.50 & -27.0 & $p\left(P_{M} \rightarrow N\right)$ & 1.81 & -25.9 \\
\hline$\sum_{i \neq M} q\left(i \rightarrow P_{M}\right)$ & 41.7 & -16.0 & $\sum_{j \neq M} p\left(P_{M} \rightarrow j\right)$ & 36.0 & -11.0 \\
\hline
\end{tabular}

NOTE: Columns 1a and 1b (resp. 3a and 3b) of the table display the average of the inflow (resp. outflow) transition probabilities of multiple jobholding in percentage points. Columns $2 \mathrm{a}$ and $2 \mathrm{~b}$ (resp. 4a and 4b) display the relative change in percent of the inflow (resp. outflow) transition probabilities of multiple jobholding between 1995 and 2015.

\section{Dynamic behavior}

Next, we analyze the dynamics of the transition probabilities in and out of multiple jobholding. It is already visible in columns 2 and 4 of Table 3 that they have both decreased over the period considered. In other words, taking on a second job has become less common, and the persistence of multiple jobholding has increased over time. 
(a) Men
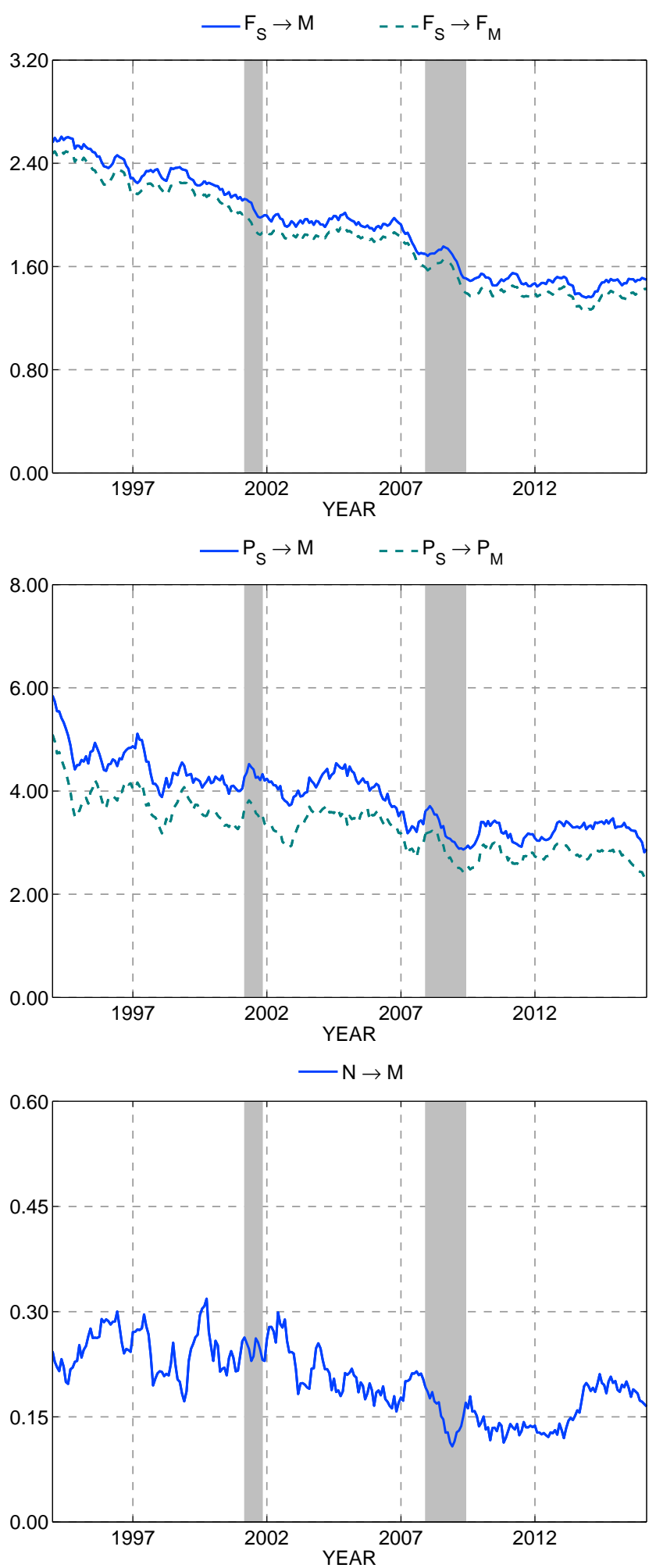

(b) Women
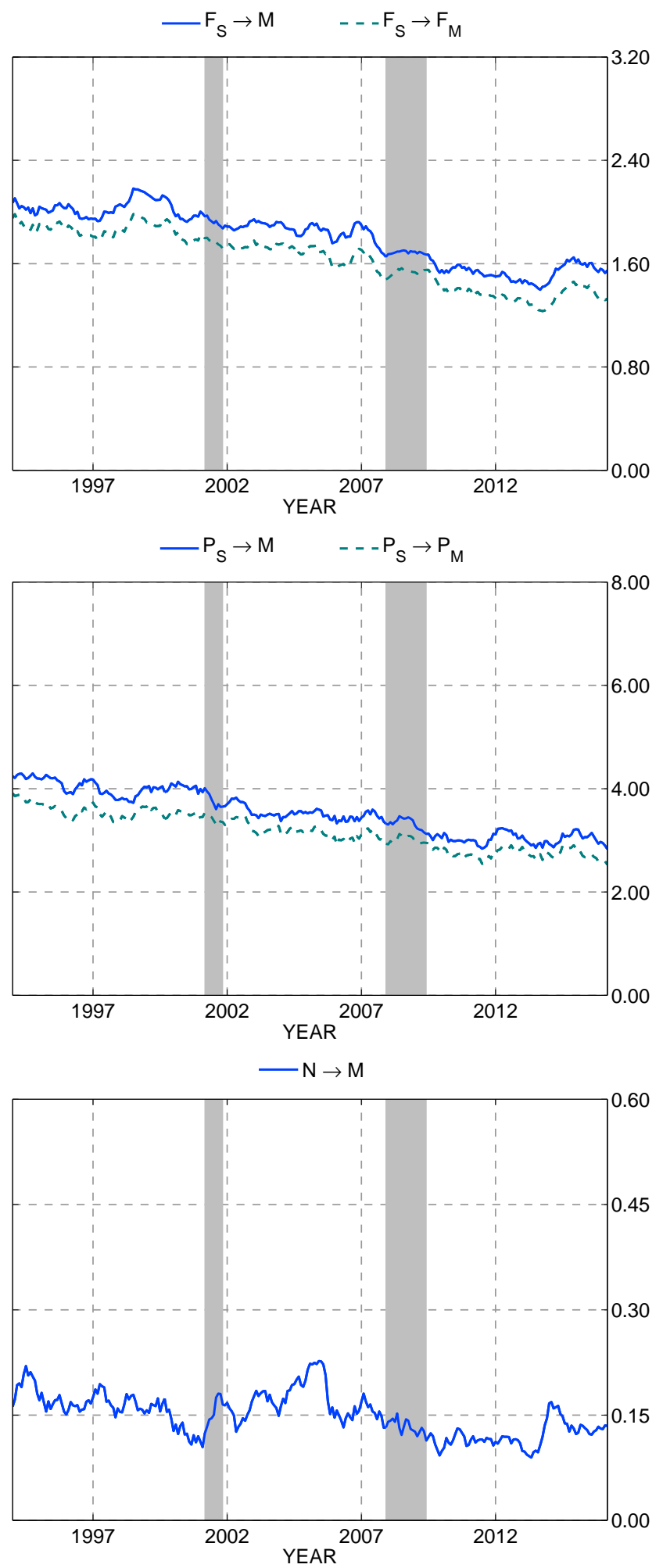

Figure 3: Monthly transition probabilities into multiple jobholding NOTE: MA-smoothed time series cleared from seasonal variations, margin error and timeaggregation bias (see Section 3 and Appendix A for details). Gray-shaded areas indicate NBER recession periods. 
(a) Men
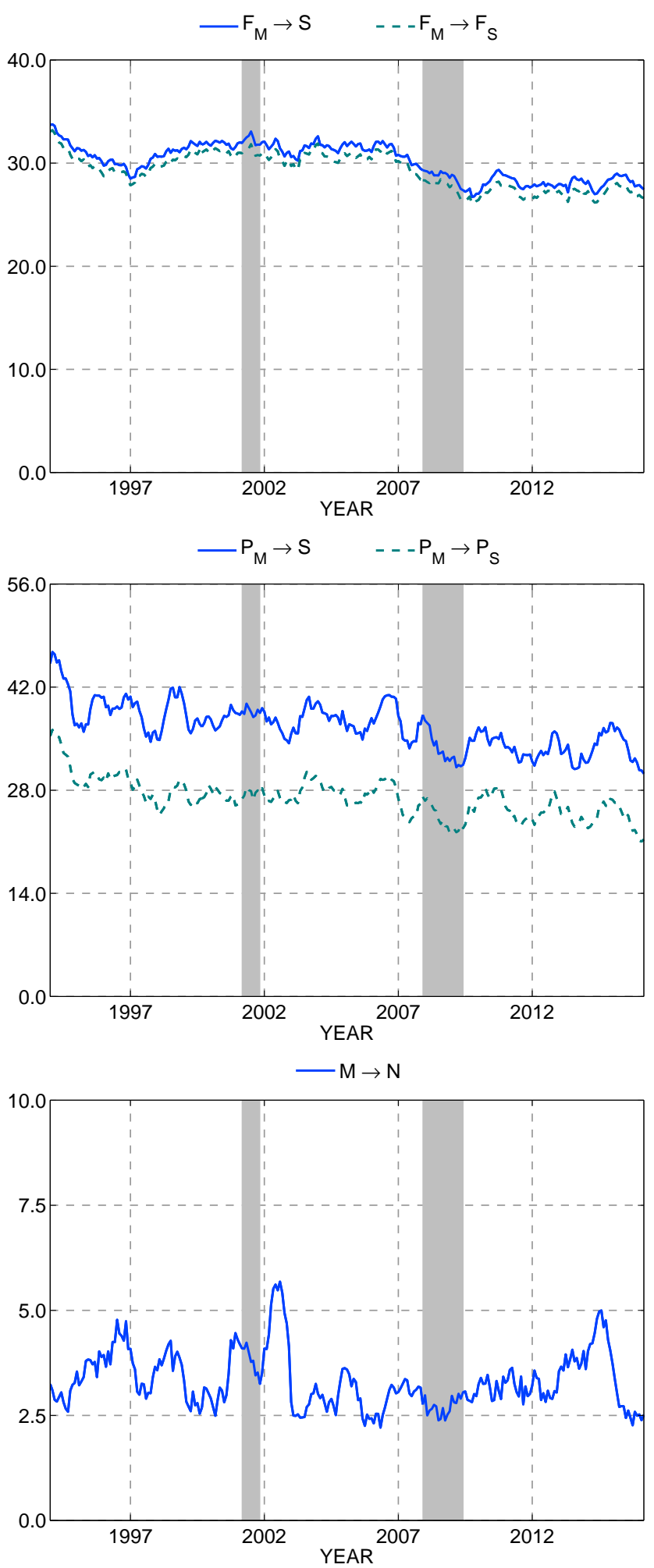

(b) Women
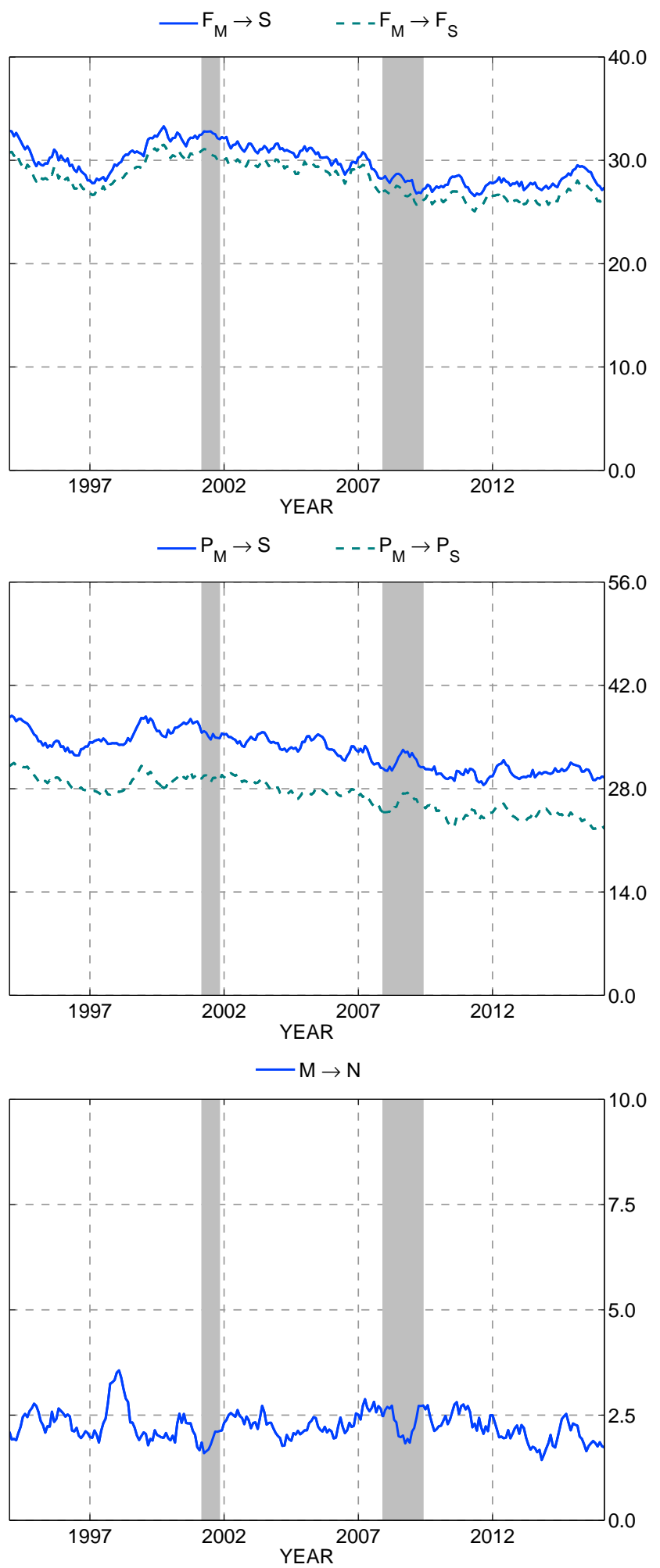

Figure 4: Monthly transition probabilities out of multiple jobholding NOTE: MA-smoothed time series cleared from seasonal variations, margin error and timeaggregation bias (see Section 3 and Appendix A for details). Gray-shaded areas indicate NBER recession periods. 
The fact that transitions from both full-time $\left(F_{S}\right)$ and part-time $\left(P_{S}\right)$ single jobholding have become less frequent implies ceteris paribus a decrease in the number of multiple jobholders. It is beyond our scope to identify the causes of this change, but nevertheless we can provide some observations. A central tenet of the analysis of multiple jobholding is that second jobs help alleviate constraints on hours that workers may be facing in their primary job (Shishko and Rostker [1976], Krishnan [1990]). Borowczyk-Martins and Lalé [2016] document that workers in the U.S. have become increasingly mobile between full-time and part-time employment. In fact, an examination of hours worked in their data suggests that individuals face an increasingly flexible work schedule. Thus, a candidate explanation for the downward trend in Figure 3 is that the 'hours constraint' motive has become less stringent over time.

The upper and middle plots of Figure 4 show that the probability to give up the second job has decreased among multiple jobholders with either a full-time $\left(F_{M}\right)$ or part-time $\left(P_{M}\right)$ primary job. These changes would generate an increase in the number of multiple jobholders at a constant inflow rate. As noted in the introduction, we think that this trend is likely to be related to self-selection into multiple jobholding. That is, if the flow into multiple jobholding shifts away from workers with a short expected duration of multiple jobholding, then a moverstayer phenomenon could drive the decrease in the probability of returning to single jobholding. This explanation seems plausible since, as just discussed, there is evidence of a weakening of the 'hours constraint' motive. Individuals who take on a second job to mitigate the constraint on hours worked are more likely to do so temporarily than, say, workers who hold a second job for noneconomic reasons (see Stinson Jr [1990] and Kimmel and Powell [1999]).

It is clear from the above discussion that the dynamics of the gross worker flows has ambiguous implications as to the evolution of multiple jobholding. For this reason, in the next section, we develop a measurement framework to analyze the downward trend in multiple jobholding.

\section{Dissecting the trend in multiple jobholding}

In this section, we assess quantitatively the contribution of changes in transition probabilities to the evolution of multiple jobholding.

\subsection{Framework}

To cast the discussion in the context of the five-state Markov chain used in Section 3, we can write the multiple jobholding rate in period $t, m_{t}$, as:

$$
m_{t}=\frac{F_{M, t}+P_{M, t}}{F_{M, t}+P_{M, t}+F_{S, t}+P_{S, t}}
$$

We follow a common practice in the "ins and outs" literature: we consider the steady-state counterpart of $m_{t}$ to quantify the role played by the dynamics of the different transition probabilities. The steady-state multiple jobholding rate in period $t, \bar{m}_{t}$, is the rate implied by the contemporaneous values of the flow hazards, which we define momentarily. The reason why it provides a good approximation of the actual multiple jobholding rate is that convergence 
towards the steady state is nearly completed within each month due to the high levels of transitions across labor market states. In fact, we find that the correlation between the actual and steady-state multiple jobholding rates is 89.9 percent.

To make the relationship between $\bar{m}_{t}$ and the transition probabilities explicit, we start by rewriting the Markov chain of equation (2) as

$$
\widetilde{\ell}_{t}=\widetilde{\boldsymbol{X}}_{t} \widetilde{\ell}_{t-1}+\mathbf{x}_{\mathbf{t}}
$$

where we denote by $\tilde{\boldsymbol{\ell}}_{t}$ the vector $\boldsymbol{\ell}_{t}$ normalized by the size of the working-age population $\left(F_{M, t}+P_{M, t}+F_{S, t}+P_{S, t}+N_{t}\right)$, and by $\widetilde{\boldsymbol{X}}_{t}$ the matrix $\boldsymbol{X}_{t}$ rearranged accordingly. Hence, the vector $\mathbf{x}_{\mathbf{t}}$ is: $\left[\begin{array}{llll}p\left(N \rightarrow F_{M}\right) & p\left(N \rightarrow P_{M}\right) & p\left(N \rightarrow F_{S}\right) & p\left(N \rightarrow P_{S}\right)\end{array}\right]_{t}^{\prime}$. It is then possible to define the continuous-time counterpart of equation (4):

$$
\dot{\tilde{\ell}}_{t}=\widetilde{\boldsymbol{H}}_{t} \widetilde{\ell}_{t}+\mathbf{h}_{\mathbf{t}}
$$

In this equation, the elements of $\widetilde{\boldsymbol{H}}_{t}$ and $\mathbf{h}_{t}$ are flow hazards, the continuous-time counterparts of the discrete-time transition probabilities. ${ }^{15} \lambda^{i j}$ denotes the flow hazard from state $i$ to state $j ; \lambda^{i j}$ can be computed using the relationship: $p(i \rightarrow j)=1-e^{-\lambda^{i j}}$. To illustrate the role of flow hazards, let us write equation (5) in explicit form:

$$
\begin{aligned}
{\left[\begin{array}{c}
\dot{\widetilde{F}}_{M} \\
\dot{\widetilde{P}}_{M} \\
\dot{\widetilde{F}}_{S} \\
\dot{\widetilde{P}}_{S}
\end{array}\right]_{t} } & {\left[\begin{array}{cccc}
-\sum_{j \neq F_{M}} \lambda^{F_{M} j}-\lambda^{N F_{M}} & \lambda^{P_{M} F_{M}}-\lambda^{N F_{M}} & \lambda^{F_{S} F_{M}}-\lambda^{N F_{M}} & \lambda^{P_{S} F_{M}}-\lambda^{N F_{M}} \\
\lambda^{F_{M} P_{M}}-\lambda^{N P_{M}} & -\sum_{j \neq P_{M}} \lambda^{P_{M} j}-\lambda^{N P_{M}} & \lambda^{F_{S} P_{M}}-\lambda^{N P_{M}} & \lambda^{P_{S} P_{M}}-\lambda^{N P_{M}} \\
\lambda^{F_{M} F_{S}}-\lambda^{N F_{S}} & \lambda^{P_{M} F_{S}}-\lambda^{N F_{S}} & -\sum_{j \neq F_{S}} \lambda^{F_{S} j}-\lambda^{N F_{S}} & \lambda^{P_{S} F_{S}}-\lambda^{N F_{S}} \\
\lambda^{F_{M} P_{S}}-\lambda^{N P_{S}} & \lambda^{P_{M} P_{S}}-\lambda^{N P_{S}} & \lambda^{F_{S} P_{S}}-\lambda^{N P_{S}} & -\sum_{j \neq P_{S}} \lambda^{P_{S} j}-\lambda^{N P_{S}}
\end{array}\right]_{t} } \\
& \times\left[\begin{array}{c}
\widetilde{F}_{M} \\
\widetilde{P}_{M} \\
\widetilde{F}_{S} \\
\widetilde{P}_{S}
\end{array}\right]_{t}+\left[\begin{array}{c}
\lambda^{N F_{M}} \\
\lambda^{N P_{M}} \\
\lambda^{N F_{S}} \\
\lambda^{N P_{S}}
\end{array}\right]_{t}
\end{aligned}
$$

At the steady state, equation (5) yields the following relationship between the stocks in vector $\widetilde{\ell}_{t}$ and the underlying flow hazards:

$$
\overline{\widetilde{\ell}}_{t}=-\widetilde{\boldsymbol{H}}_{t}^{-1} \mathbf{h}_{t}
$$

One can then approximate each steady-state stock at time $t$, say $\overline{\widetilde{\ell}}_{t}$, with a Taylor expansion:

$$
\overline{\tilde{\ell}}_{t}-\overline{\tilde{\ell}} \approx \sum_{i \neq j} \frac{\partial \overline{\widetilde{\ell}}_{t}}{\partial \lambda^{i j}}\left(\lambda_{t}^{i j}-\lambda^{i j}\right) .
$$

\footnotetext{
${ }^{15}$ The upper dot on $\widetilde{\ell}_{t}$ in the left-hand side of equation (5) denotes its first-order time derivative. Notice that on the right-hand side of this equation, $\widetilde{\boldsymbol{H}}_{t}$ multiplies the time- $t$ vector $\widetilde{\boldsymbol{\ell}}_{t}$ whereas in equation (4) $\widetilde{\boldsymbol{X}}_{t}$ multiplies the vector of stocks from time $t-1$.
} 
The notations without a time subscript $t$ denote the sample mean of a variable and $\frac{\partial \overline{\tilde{\ell}}_{t}}{\partial \lambda^{i j}}$ are partial derivatives. The last step is to relate the deviation of stocks from their respective sample mean to the evolution of the steady-state multiple jobholding rate. By totally differentiating the steady-state counterpart of equation (3), we have:

$$
d \bar{m}_{t}=\frac{\left(d \bar{F}_{M, t}+d \bar{P}_{M, t}\right)\left(1-\bar{m}_{t}\right)-\left(d \bar{F}_{S, t}+d \bar{P}_{S, t}\right) \bar{m}_{t}}{\bar{F}_{M, t}+\bar{P}_{M, t}+\bar{F}_{S, t}+\bar{P}_{S, t}}
$$

where the letter $d$ denotes the deviation of a stock from its mean. Then, we can combine equations (8) and (9) to construct counterfactual changes in the multiple jobholding rate driven by changes in each flow hazard. Also, owing to the linearity of equation (8), we can construct counterfactual changes driven by changes in a group of flow hazards (e.g. inflows, outflows, etc.) by simply adding the individual counterfactual time series.

\subsection{Changes across decades}

We use the framework developed in the previous subsection to compute two sets of results. ${ }^{16}$ In the first application, we study the changes of the (steady-state) multiple jobholding rate implied by the behavior of specific flow hazards or groups of flow hazards over each decade. Specifically, using equation (9), we compute various counterfactual changes, $\Delta \bar{m}$, defined by:

$$
\Delta \bar{m}=\sum_{\tau=t_{0}}^{t_{1}} d \bar{m}_{\tau}
$$

to analyze the changes between two periods, $t_{0}$ and $t_{1}$. The results of these calculations are reported in Table 4.

To illustrate how the table works, we comment the entries of column 3 in panel a. Between 1995 and 2015, the evolution of the transition probability $p\left(F_{S} \rightarrow M\right)$ per se implies a change of the multiple jobholding rate of male workers by -2.17 percentage points (pp.). The corresponding figure for $p\left(P_{S} \rightarrow M\right)$ is $-0.29 \mathrm{pp}$. Adding up the changes driven by the probabilities into multiple jobholding $\left(F_{S} \rightarrow M, P_{S} \rightarrow M\right.$ and $N \rightarrow M$ ), the impact is a change by -2.49 pp. of the multiple jobholding rate. On the other hand, the predicted change based on the behavior of $p\left(M \rightarrow F_{S}\right)$ and $p\left(M \rightarrow P_{S}\right)$ is an increase by 0.14 and 0.35 pp., respectively. The cumulated effect of the probabilities to leave multiple jobholding is an increase by $0.51 \mathrm{pp}$. Next, we add the changes implied by the transition probabilities: together they result in a change of the multiple jobholding rate by $-1.97 \mathrm{pp}$. For comparison, the actual change of the steady-state multiple jobholding rate is -1.90 pp. ${ }^{17}$

\footnotetext{
${ }^{16}$ Although we do not pursue this route here, we can repeat the analysis using the time series cleared from their high-frequency variations. The results (available upon request) are robust to these modifications.

${ }^{17}$ There are two reasons for the difference between the predicted change and the actual change of $\bar{m}_{t}$. First, we rely on a Taylor expansion in equation (8), which by construction approximates the evolution of steady-state stocks. Second, the predicted change reported in Table 4 adds up the changes only driven by the transition probabilities in and out of multiple jobholding. Thus, it ignores the indirect changes coming from the other transition probabilities, e.g. $F_{S} \rightarrow P_{S}, P_{S} \rightarrow F_{S}$, etc. In principle, these transition have also an impact on the multiple jobholding rate because they change the relative size of the pool of entrants into multiple jobholding.
} 
Table 4: Counterfactual changes of the multiple jobholding rate

1995 to 20052005 to $2015 \quad 1995$ to 2015

(1)

(a) Men

$\begin{array}{cccc}\Delta \bar{m}\left(F_{S} \rightarrow M\right) & -1.23 & -0.94 & -2.17 \\ \Delta \bar{m}\left(P_{S} \rightarrow M\right) & -0.07 & -0.22 & -0.29 \\ \sum_{i \neq M} \Delta \bar{m}(i \rightarrow M) & -1.35 & -1.14 & -2.49 \\ \Delta \bar{m}\left(F_{M} \rightarrow S\right) & 0.07 & 0.07 & 0.14 \\ \Delta \bar{m}\left(P_{M} \rightarrow S\right) & -0.19 & 0.55 & 0.35 \\ \sum_{j \neq M} \Delta \bar{m}(M \rightarrow j) & -0.13 & 0.65 & 0.51 \\ \text { Predicted } & -1.48 & -0.49 & -1.97 \\ \text { Actual } & -1.46 & -0.45 & -1.90\end{array}$

(b) Women

$\begin{array}{llll}\Delta \bar{m}\left(F_{S} \rightarrow M\right) & -0.29 & -0.51 & -0.80 \\ \Delta \bar{m}\left(P_{S} \rightarrow M\right) & -0.42 & -0.23 & -0.64 \\ \sum_{i \neq M} \Delta \bar{m}(i \rightarrow M) & -0.68 & -0.82 & -1.51 \\ \Delta \bar{m}\left(F_{M} \rightarrow S\right) & -0.02 & 0.30 & 0.27 \\ \Delta \bar{m}\left(P_{M} \rightarrow S\right) & -0.09 & 0.21 & 0.12 \\ \sum_{j \neq M} \Delta \bar{m}(M \rightarrow j) & -0.10 & 0.52 & 0.42 \\ \text { Predicted } & -0.79 & -0.30 & -1.09 \\ \text { Actual } & -0.87 & -0.30 & -1.17\end{array}$

NOTE: The entries in the table are counterfactual changes of the multiple jobholding rate reported in percentage points. See the text of Subsection 4.2 for details.

\section{Results}

The first remark concerns the fit of the counterfactual time series. As can be seen at the bottom of each panel in Table 4, the changes based on the behavior of the inflows and outflows track the evolution of the steady-state multiple jobholding rate well. In addition, they capture the differences in the size of the change between men and women, which we noted in Subsection 2.3, as well as its timing. That is, the decrease of the multiple jobholding rate is almost twice larger for male workers, and three quarters of the decline occur during the decade 1995-2005 for both men and women.

Next, we note that the changes driven by the inflows reduce the multiple jobholding rate, whereas those driven by the outflows increase it. This is in line with the discussion from Subsection 3.3. Taken in isolation, the fall in the probability to take a second job (Figure 3) among male workers predicts a decrease in multiple jobholding by $2.49 \mathrm{pp}$. between 1995 and 2015, which is more than 30 percent higher than the actual change (-1.90 pp.). For women, the corresponding figures are $-1.51 \mathrm{pp}$. and $-1.17 \mathrm{pp}$, resulting in an overprediction of the same magnitude (30 percent). The fact that the inflows and outflows yield predicted changes that exceed the actual ones underscores a conclusion of the paper, that the evolution of multiple jobholding masks larger changes in the underlying worker flows. Finally, we observe that this 
conclusion is more relevant for the 2005-2015 decade than for the 1995-2005 decade. Without our measurement framework, it is difficult to notice the difference between these two periods.

Our approach distinguishes between full-time and part-time work when individuals hold either one or several jobs. This is especially relevant to understand the evolution of multiple jobholding among female workers. As can be seen in column 1 of Table 4, during the 19952005 decade when their multiple jobholding rate fell by 0.87 pp., transitions from part-time single jobholding per se explain a decrease by $0.42 \mathrm{pp}$. What is perhaps surprising is that part-time work is also of consequence to the evolution of the multiple jobholding rate of male workers, at least during 2005-2015 decade. The fact that transitions from multiple jobholding with a part-time primary job to single jobholding decreased could have led to an increase by $0.55 \mathrm{pp}$. of their multiple jobholding rate. Thus, without this upward trend, the decrease observed in that period would have been more than twice larger than the actual change $(-0.45$ pp.). These observations illustrate, again, the usefulness of this measurement framework which reveals changes that may go unnoticed otherwise.

To summarize: (i) for both men and women, the trend is overwhelmingly explained by the dwindling propensity of workers to take on a second job; (ii) the change in transitions in the opposite direction mitigated the decline in multiple jobholding (leading to a 'stock-flow fallacy' during the 2005-2015 decade, when changes in stocks are much lower than the changes implied by the gross flows taken in isolation); (iii) distinguishing between full-time and part-time work helps establish a clear picture of the evolution of multiple jobholding.

\subsection{Variance decomposition}

In order to get a synthetic view of the results, we measure the variance contribution of the different transition probabilities over the sample period. Specifically, in Table $5, \beta(i \rightarrow j)$ shows the contribution (in percent) to the variance of $d \bar{m}_{t}$ of the counterfactual multiple jobholding rate driven by changes in transitions from $i$ to $j$.

Table 5: Variance decomposition of the multiple jobholding rate

\begin{tabular}{|c|c|c|c|}
\hline \multicolumn{2}{|l|}{$\begin{array}{c}\text { Inflows } \\
(1)\end{array}$} & \multicolumn{2}{|l|}{$\begin{array}{c}\text { Outflows } \\
(2)\end{array}$} \\
\hline$\beta\left(F_{S} \rightarrow M\right)$ & 84.4 & $\beta\left(F_{M} \rightarrow S\right)$ & -8.2 \\
\hline$\beta\left(P_{S} \rightarrow M\right)$ & 25.5 & $\beta\left(P_{M} \rightarrow S\right)$ & -3.1 \\
\hline$\beta(N \rightarrow M)$ & 2.5 & $\beta(M \rightarrow N)$ & 0.2 \\
\hline$\sum_{i \neq M} \beta(i \rightarrow M)$ & 112.4 & $\sum_{j \neq M} \beta(M \rightarrow j)$ & -11.0 \\
\hline
\end{tabular}

NOTE: The entries in column 1 (resp. 2) show the variance contribution in percent of the inflows (resp. outflows) to the evolution of the multiple jobholding rate.

In line with the picture we have been constructing thus far, we see that the inflows are predominant, and that they overexplain (by 12.4 percent) the variance of $d \bar{m}_{t}$. The extra decline in multiple jobholding is offset by the behavior of the outflows, i.e. the fact that 
multiple jobholding became more persistent during the past decades. Finally, while part-time work is relevant to understand changes in the inflows and outflows (cf. Subsection 4.2), it often implies changes in stocks that cancel each other out. This leaves transitions from holding a single full-time job as the main source of variations in the multiple jobholding rate. To summarize with one number, explaining the behavior of the transition probability $p\left(F_{S} \rightarrow M\right)$ amounts to explaining almost 85 percent of the evolution of multiple jobholding.

\section{$5 \quad$ Discussion and concluding remarks}

There are multiple signs of shifts in the labor supply behaviors of U.S. workers during a recent period. ${ }^{18}$ This section is an attempt to decipher whether these shifts could help understand the decrease in the propensity of single jobholders to take on a second job.

Barnichon and Figura [2015] document a decline in 'desire to work' in the U.S. labor market: the fraction of individuals out of the labor force who report that they want either a full-time or part-time job has decreased substantially over time. Figures 3 and 5 in their paper shows that the trend was concentrated during the second half of the 1990s. Thus, the timing fits well with the facts analyzed in the previous sections. Meanwhile, they also document that the decline occurs mainly among prime-age females in low-income, non-single households. We find, on the other hand, that the decline in multiple jobholding is stronger for men, and marital status has almost no impact on the trend (see, for instance, panel $d$ in Table 1). These differences are perhaps not sufficient to rule out that a declining 'desire to work more' drives the trend in multiple jobholding. Barnichon and Figura [2015] study a type of time-varying heterogeneity among individuals out of the labor force. It may well be that this heterogeneity is correlated with a different set of observable characteristics for employed individuals.

Hall [2016] and Hall and Petrosky-Nadeau [2016] show that during the past 15 years, primeage workers in households from the higher half of the income distribution have reduced their propensity to participate in the labor force. ${ }^{19}$ It seems that, to some extent, this is inconsistent with the result that declining 'desire to work' is a low-income household phenomenon. Reconciling these observations is not under the scope of this paper. We note, meanwhile, that Hall and Petrosky-Nadeau [2016]'s finding dovetails with the fact that multiple jobholding is likely to be a higher-income household phenomenon. At least two features support this idea. First, the propensity to take on second jobs is higher among individuals with higher education and/or who are employed in better-paying occupations. Second, it is common for workers in these occupations to be salaried rather than paid by the hour, which makes multiple jobholding a more likely margin of adjustment to increase earnings. ${ }^{20}$ Kuhn and Lozano [2008] report

\footnotetext{
${ }^{18}$ Although we emphasize labor supply changes in this section, we do not rule out that labor demand could play a role in driving the trend in multiple jobholding. It is however difficult to relate labor demand to our findings: whether a job is a second job is inherently dependent on the worker. To our knowledge, there exists a (weak) correlation between certain job characteristics and the probability that it serves as a second job. It is not clear how to extrapolate from these characteristics so as to obtain, say, vacancy data on second jobs.

${ }^{19}$ There is a strand of research on the reduction of labor force participation among prime-age men over a longer period of time; see Juhn and Potter [2006] for a survey of this literature.

${ }^{20}$ Hirsch et al. [2016a] offer an interesting discussion of this point. They note that, while the literature has paid considerable attention to the 'hours constraint' (e.g., Shishko and Rostker [1976], Krishnan [1990],
} 
another feature that matches these facts well. They document a change in labor supply for salaried workers in jobs where financial bonuses reward hours worked above the contracted minimum. Thus, we think that the decline in the propensity to take on a second job could be another manifestation of those shifts in the labor supply behavior of individuals in high-income households uncovered by Hall and Petrosky-Nadeau [2016].

It is well known that, over a period longer than the past 20 years, there has been a shift away from allocating hours to market activities (e.g. Aguiar and Hurst [2007], Ramey and Francis [2009]). A question for future work is whether the decline of multiple jobholding is part of this secular trend. The evolution of the multiple jobholding rate actually coincides with some changes in hours worked among single jobholders worthy of attention. Specifically, Lalé [2015] and Borowczyk-Martins and Lalé [2016] find that hours worked in part-time jobs have increased over time, and that single jobholders tend to rotate more often between full-time and part-time employment. It is unclear whether this could offset the reduction of time allocated to market work prompted by the decline of multiple jobholding. First, the differences in hours worked between multiple and single jobholders are large. For example, Hipple [2010] reports that multiple jobholders work on average 11 more hours per week compared to single jobholders. Second, in addition to hours worked on the job, a second job may entail commute time, set-up costs, etc. which further decrease the amount of time allocated to housework and leisure. The data collected in time-use surveys could help shed light on these questions.

\section{Conclusion}

Single jobholders, especially those with a full-time job, have become less likely to work at a second job. As a result, the multiple jobholding rate in the U.S. labor market has declined substantially during the past two decades. This may be due to changes in the economic and noneconomic reasons that prompt individuals to take second jobs. At the same time, it seems likely that the decline of multiple jobholding is part of a broader trend, visible in the lower labor force participation of prime-age U.S. workers in the last 15 to 20 years. Understanding the shifts in work opportunities and work incentives that drive these phenomena is an important avenue for future research.

\section{References}

Katharine Abraham, John C Haltiwanger, Kristin Sandusky, and James R Spletzer. Measuring the 'gig' economy. Mimeo, University of Maryland, 2015.

Mark Aguiar and Erik Hurst. Measuring trends in leisure: The allocation of time over five decades. Quarterly Journal of Economics, 122(3):969-1006, 2007.

Thomas Amirault. Characteristics of multiple jobholders, 1995. Monthly Labor Review, 120(3): 9-15, 1997.

or Paxson and Sicherman [1994]), the 'earnings constraint' motive could also be relevant to analyze multiple jobholding. One telling example emphasized by Hirsch et al. [2016a] are teachers: they are more likely to face a constraint on earnings rather than hours, and their schedule is usually flexible enough to work a second job. 
Catalina Amuedo-Dorantes and Jean Kimmel. Moonlighting over the business cycle. Economic Inquiry, 47(4):754-765, 2009.

Susan L Averett. Moonlighting: Multiple motives and gender differences. Applied Economics, 33(11):1391-1410, 2001.

Regis Barnichon and Andrew Figura. Declining desire to work and downward trends in unemployment and participation. NBER Macroeconomics Annual, 30:449-494, 2015.

Daniel Borowczyk-Martins and Etienne Lalé. The rise of part-time employment. Sciences Po Discussion paper 2016-04, April 2016.

Sharon R Cohany, Anne E Polivka, and Jennifer M Rothgeb. Revisions in the Current Population Survey effective January 1994. Employment and Earnings, 41:13-37, 1994.

Michael WL Elsby, Bart Hobijn, and Ayşegül Şahin. On the importance of the participation margin for labor market fluctuations. Journal of Monetary Economics, 72:64-82, 2015.

Shigeru Fujita and Garey Ramey. The cyclicality of separation and job finding rates. International Economic Review, 50(2):415-430, 2009.

Leo A Goodman. Statistical methods for the mover-stayer model. Journal of the American Statistical Association, 56(296):841-868, 1961.

Robert Hall and Nicolas Petrosky-Nadeau. Changes in labor participation and household income. FRBSF Economic Letter, 02, 2016.

Robert E Hall. The anatomy of stagnation in a modern economy. Mimeo, Stanford University, 2016.

Steven F Hipple. Multiple jobholding during the 2000s. Monthly Labor Review, 133(7):21-32, 2010.

Barry T Hirsch and John V Winters. Rotation group bias in measures of multiple job holding. Economic Letters, Forthcoming, pages 160-163, 2016.

Barry T Hirsch, Muhammad M Husain, and John V Winters. Multiple job holding, local labor markets, and the business cycle. IZA Journal of Labor Economics, 5(1):1-29, 2016a.

Barry T Hirsch, Muhammad M Husain, and John V Winters. The puzzling fixity of multiple job holding across regions and labor markets. IZA Discussion paper 9631, January 2016b.

Chinhui Juhn and Simon Potter. Changes in labor force participation in the United States. Journal of Economic Perspectives, 20(3):27-46, 2006.

Hyman B Kaitz. Analyzing the length of spells of unemployment. Monthly Labor Review, 93 (11):11-20, 1970. 
Lawrence F Katz and Alan B Krueger. The rise and nature of alternative work arrangements in the United States, 1995-2015. NBER Working Paper 22667, 2016.

Jean Kimmel and Lisa M Powell. Moonlighting trends and related policy issues in Canada and the United States. Canadian Public Policy, 25(2):207-231, 1999.

Jean Kimmel and Karen Smith Conway. Who moonlights and why? Evidence from the SIPP. Industrial Relations: A Journal of Economy and Society, 40(1):89-120, 2001.

Pramila Krishnan. The economics of moonlighting: A double self-selection model. Review of Economics and Statistics, 72(2):361-67, 1990.

Alan Krueger, Alexandre Mas, and Xiaotong Niu. The evolution of rotation group bias: Will the real unemployment rate please stand up? Review of Economics and Statistics, Forthcoming, 2016.

Peter Kuhn and Fernando Lozano. The expanding workweek? Understanding trends in long work hours among US men, 1979-2006. Journal of Labor Economics, 26(2):311-343, 2008.

Etienne Lalé. Multiple jobholding over the past two decades. Monthly Labor Review, 138, 2015.

Jennifer L Martel. Reasons for working multiple jobs. Monthly Labor Review, 123(10):42-43, 2000.

Maite Martinez-Granado. Testing labour supply and hours constraints. Labour Economics, 12 (3):321-343, 2005.

Georgios A Panos, Konstantinos Pouliakas, and Alexandros Zangelidis. Multiple job holding, skill diversification, and mobility. Industrial Relations: A Journal of Economy and Society, $53(2): 223-272,2014$.

Christina H Paxson and Nachum Sicherman. The dynamics of dual-job holding and job mobility. Journal of Labor Economics, 14(3):357-393, 1994.

George L Perry. Unemployment flows in the US labor market. Brookings Papers on Economic Activity, 3(2):245-292, 1972.

Thomas J Plewes and John F Stinson Jr. The measurement and significance of multiple jobholding in the United States. Statistical Journal of the United Nations Economic Commission for Europe, 8(1):57-67, 1991.

James M. Poterba and Lawrence H Summers. Reporting errors and labor market dynamics. Econometrica, 54(6):1319-38, 1986.

Valerie A Ramey and Neville Francis. A century of work and leisure. American Economic Journal: Macroeconomics, 1(2):189-224, 2009.

Robert Shimer. Reassessing the ins and outs of unemployment. Review of Economic Dynamics, 15(2):127-148, 2012. 
Robert Shishko and Bernard Rostker. The economics of multiple job holding. American Economic Review, 66(3):298-308, 1976.

Milena Simic and Sachin Sethi. People with second jobs. Labour Market Trends, 110:239-247, 2002.

Alexandra B Stanczyk, Julia R Henly, and Susan J Lambert. Enough time for housework? Low-wage work and desired housework time adjustments. Journal of Marriage and Family, (forthcoming), 2016.

John F Stinson Jr. Multiple jobholding up sharply in the 1980s. Monthly Labor Review, 113 (7):3-10, 1990.

Deborah Sussman. Moonlighting: A growing way of life. Perspectives on Labour and Income, 10(2):24, 1998.

Nellie L Zhao. Search and multiple jobholding. Mimeo, Cornell University, 2016. 


\section{Supplementary material (for online publication)}

\section{A Correction procedures}

Our time series of stocks and gross worker flows are subject to several adjustments. First, we remove potential outliers, both additive and transitory, and we filter out systematic seasonal variations using the Census Bureau's X-13ARIMA-SEATS program. Using the filtered time series, we divide the gross flow of workers from state $i$ to state $j$ at time $t$ by the stock of worker in state $i$ at time $t-1$ to obtain the time- $t$ transition probability $p(i \rightarrow j)$. Then we adjust the set of these transition probabilities to account for margin error and time aggregation.

\section{Margin error}

The goal of margin-error adjustments is to address the discrepancy between the stocks and the gross flows. The stocks are computed using cross-sectional data 'only'; the gross flows, on the other hand, require longitudinal linking, and therefore their measurement suffers from sample attrition, imperfect matching, etc. The margin-error adjustment below reconciles the predicted changes in stocks with the actual changes calculated using cross-sectional data.

The starting point of the analysis is the Markov chain structure that underlies our approach in Section 3. For convenience, we repeat equation (2) here:

$$
\ell_{t}=\boldsymbol{X}_{t} \ell_{t-1}
$$

In this equation, $\boldsymbol{\ell}_{t}$ is a vector of the stocks in each of the states of the Markov chain, and $\boldsymbol{X}_{t}$ is a stochastic matrix. We follow Elsby et al. [2015] and rewrite the dynamics of changes in stocks in the following way:

$$
\Delta \boldsymbol{\ell}_{t}=\boldsymbol{S}_{t-1} \boldsymbol{p}_{t}
$$

$\boldsymbol{p}_{t}$ is a column vector containing all time-t $p(i \rightarrow j)$ such that $i \neq j$, and $\boldsymbol{S}_{t-1}$ is a conformable matrix of stocks in the previous period. Of course, we only observe (compute) the unadjusted transition probabilities, which we denote as $\widehat{\boldsymbol{p}}_{t}$. In equation (12) on the other hand, $\boldsymbol{p}_{t}$ denotes stock-consistent transition probabilities. We recover $\boldsymbol{p}_{t}$ by minimizing the weighted sum of squares of margin-error adjustments under the constraint of equation (12), i.e. we solve:

$$
\min \left(\boldsymbol{p}_{t}-\widehat{\boldsymbol{p}}_{t}\right)^{\prime} \boldsymbol{W}_{t}^{-1}\left(\boldsymbol{p}_{t}-\widehat{\boldsymbol{p}}_{t}\right) \text { s.t. } \Delta \boldsymbol{\ell}_{t}=\boldsymbol{S}_{t-1} \boldsymbol{p}_{t}
$$

In this minimization problem, $\boldsymbol{W}_{t}$ is a weighing matrix proportional to the covariance matrix of $\widehat{\boldsymbol{p}}_{t}$ (see Elsby et al. [2015] for details). The solution of this minimization problem, $\boldsymbol{p}_{t}$, is a function of $\widehat{\boldsymbol{p}}_{t}, \boldsymbol{S}_{t-1}$ and $\Delta \boldsymbol{\ell}_{t}$ which we already have in hand. We comment on the effects of margin-error adjustments in Appendix B.1 below. 


\section{Time-aggregation bias}

The idea behind the adjustment for time-aggregation bias is explained in Subsection 3.2. Our adjustment procedure is based on the continuous-time correction developed by Shimer [2012]. We describe it here briefly for completeness.

To maintain consistency with the notations of Section 4, denote by $\boldsymbol{H}_{t}$ the continuous-time analog of $\boldsymbol{X}_{t}$. It is known that if the eigenvalues of $\boldsymbol{H}_{t}$ are all distinct, then $\boldsymbol{H}_{t}$ can be written as: $\boldsymbol{H}_{t}=\boldsymbol{V}_{t} \boldsymbol{C}_{t} \boldsymbol{V}_{t}^{-1}$, where $\boldsymbol{C}_{t}$ is a diagonal matrix of eigenvalues and $\boldsymbol{V}_{t}$ is the matrix of associated eigenvectors. Furthermore, one can show that $\boldsymbol{X}_{t}$ can be decomposed as: $\boldsymbol{X}_{t}=\boldsymbol{V}_{t} \boldsymbol{D}_{t} \boldsymbol{V}_{t}^{-1}$, where $\boldsymbol{D}_{t}$ is a diagonal matrix whose elements are the exponentiated eigenvalues in $\boldsymbol{C}_{t}$, and that this relationship is unique if the eigenvalues of $\boldsymbol{D}_{t}$ are, in addition to distinct, real and nonnegative. These relationships can be used to obtain time series of estimates of the adjusted hazard rates $\lambda_{t}^{i j}$. In every period $t$, we compute the eigenvalues of the discrete transition matrix $\boldsymbol{X}_{t}$ and check whether they are all distinct, real and nonnegative. We then take their natural logarithm to obtain the eigenvalues of the continuous-time analogue $\boldsymbol{H}_{t}$. Finally, we compute $\lambda_{t}^{i, j}$, and use the relationship: $p_{t}(i \rightarrow j)=1-e^{-\lambda_{t}^{i j}}$ to obtain a series of time-aggregation adjusted transition probabilities.

\section{B Additional results}

This appendix contains additional information on the role of margin error (B.1), rotation bias (B.2), and more detailed results for some subgroups of the population (B.3).

\section{B.1 Margin-error adjustment}

Our adjustment procedures are applied consecutively to the data. In Subsection 3.2, we described the role of the last adjustment, i.e. the correction of time-aggregation bias. Table B1 compares it to the role of the adjustment immediately before, namely the margin-error correction.

By looking at columns 3 and 6 of Table B1, we see that the adjustments of the inflows implied by time aggregation tend to be larger than those coming from margin error. This is true especially for the transition probability from part-time single jobholding $\left(P_{S}\right)$ to multiple jobholding $(M)$ : it increases by 16.9 percent after the first adjustment and by 34.8 percent after the second one. That said, the magnitude of the margin-error correction is not too far off compared to the time-aggregation correction. For transitions in the opposite direction, margin error actually plays a comparable or even larger role than time aggregation. For instance, these adjustments lead to changes by respectively -13.3 percent and 3.51 percent of the transition probability from multiple jobholding with a full-time primary job $\left(F_{M}\right)$ to single jobholding $(S)$. This is noteworthy because the impact of margin error on the levels of transition probabilities is usually much lower than the adjustments implied by time-aggregation bias (see, e.g., Shimer [2012] and Elsby et al. [2015]).

For completeness, we report the relative change in the main transition probability from the data not adjusted for either margin error or time aggregation (column 1) and the final 
Table B1: Role of the adjustments addressing margin error and time-aggregation bias

\begin{tabular}{|c|c|c|c|c|c|c|}
\hline & \multicolumn{3}{|c|}{ Margin error } & \multicolumn{3}{|c|}{ Time aggregation } \\
\hline & $\begin{array}{c}\text { Unadjusted } \\
(1)\end{array}$ & $\begin{array}{c}\text { Adjusted } \\
(2)\end{array}$ & $\begin{array}{c}\triangle \\
(3)\end{array}$ & $\begin{array}{c}\text { Unadjusted } \\
(4)\end{array}$ & $\begin{array}{c}\text { Adjusted } \\
(5)\end{array}$ & $\triangle{ }_{(6)}$ \\
\hline \multicolumn{7}{|l|}{ (a) Inflows } \\
\hline$F_{S} \rightarrow M$ & 1.31 & 1.57 & 0.26 & 1.57 & 1.87 & 0.30 \\
\hline$P_{S} \rightarrow M$ & 2.29 & 2.68 & 0.39 & 2.68 & 3.61 & 0.93 \\
\hline$N \rightarrow M$ & 0.19 & 0.24 & 0.04 & 0.24 & 0.16 & -0.08 \\
\hline \multicolumn{7}{|c|}{ (b) Outflows } \\
\hline$F_{M} \rightarrow S$ & 33.3 & 28.9 & -4.41 & 28.9 & 29.9 & 1.01 \\
\hline$P_{M} \rightarrow S$ & 33.1 & 29.9 & -3.21 & 29.9 & 34.1 & 4.25 \\
\hline$M \rightarrow N$ & 4.19 & 3.72 & -0.48 & 3.72 & 2.37 & -1.34 \\
\hline
\end{tabular}

NOTE: Columns 1, 2, 4, 5 of the table display the average of transition probabilities. Column 3 (resp. 6) reports the difference between the unadjusted and adjusted figures displayed in columns 1 and 2 (resp. 4 and 5) of the table. By definition, the adjusted data in column 2 is referred to as

'unadjusted data' in column 4 . The entries of the table are in percentage points.

data (column 5): on average, $p\left(F_{S} \rightarrow M\right)$ increases by 43.0 percent, $p\left(P_{S} \rightarrow M\right)$ increases by 57.6 percent, $p\left(F_{M} \rightarrow S\right)$ decreases by 10.2 percent and $p\left(P_{M} \rightarrow S\right)$ increases by 3.15 percent. Thus, the changes are especially large for the inflows. Finally, there is a feature that is not visible in Table B1: in the unadjusted data, the transition probability from multiple jobholding with a full-time primary job $\left(F_{M}\right)$ to single jobholding $(S)$ increases between 1995 and 2015, which is unlike in the adjusted data (cf. Figure 4). These findings reinforce a conclusion of the paper, that previous estimates of the transition probabilities (e.g. Lalé [2015]) give an incomplete picture of the evolution of multiple jobholding.

\section{B.2 Rotation group bias}

Hirsch and Winters [2016] report a significant 'rotation bias' in the CPS data on multiple jobholding. Recall from Subsection 2.1 that there are two rounds of four monthly interviews in the CPS survey. Hirsch and Winters [2016] document that the multiple jobholding rate is higher in the first rotation group of each of these survey rounds, which are usually referred to as the 'month in sample 1' (MIS1) and 'month in sample 5' (MIS5) rotation groups. The authors' assessment is that CPS respondents are more engaged with the survey during MIS 1 and 5 than during the subsequent months, and that the quality of their responses is higher also because the interviews are often conducted in person during MIS 1 and 5 .

Figures B1 and B2 display, respectively, the main transition probabilities measured within different samples. The solid line denotes the baseline: the flow data include linked CPS respondents from any of non-outgoing rotation groups. The dashed line denotes data which use only respondents from the pooled MIS1 and MIS5 samples. The dashed-dotted line is based on an even smaller sample, namely the MIS1 sample.

Rotation group bias undeniably affects the estimates of transition probabilities into multiple jobholding. Indeed, in Figure B1, we see that the levels of the transition probabilities are sys- 
(a) $\mathrm{F}_{\mathrm{S}} \rightarrow \mathrm{M}$

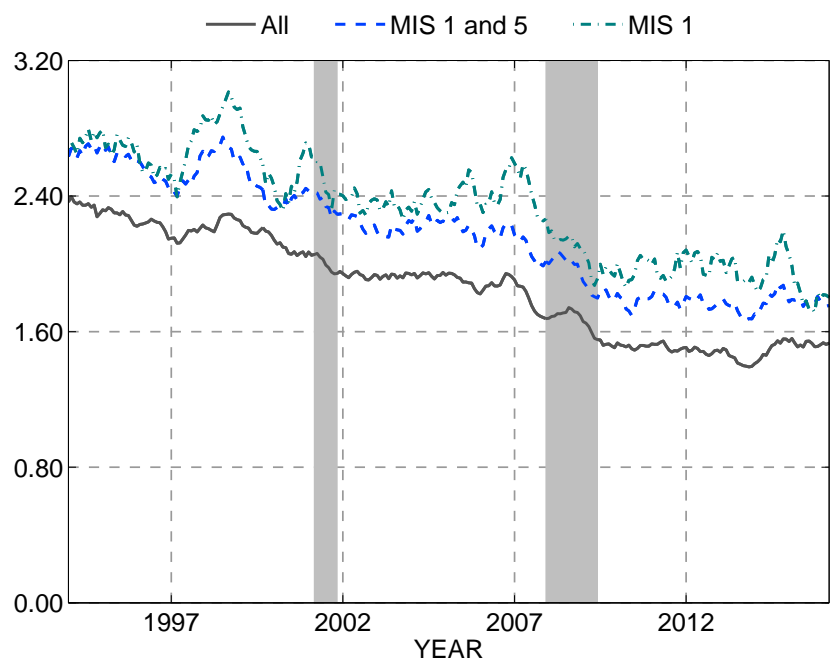

(b) $\mathrm{P}_{\mathrm{S}} \rightarrow \mathrm{M}$

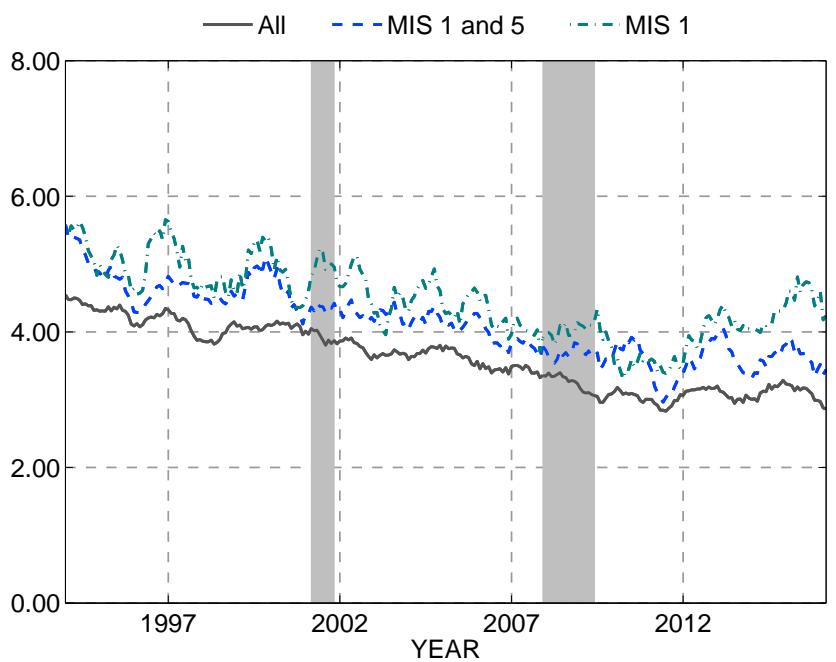

(c) $\mathrm{N} \rightarrow \mathrm{M}$

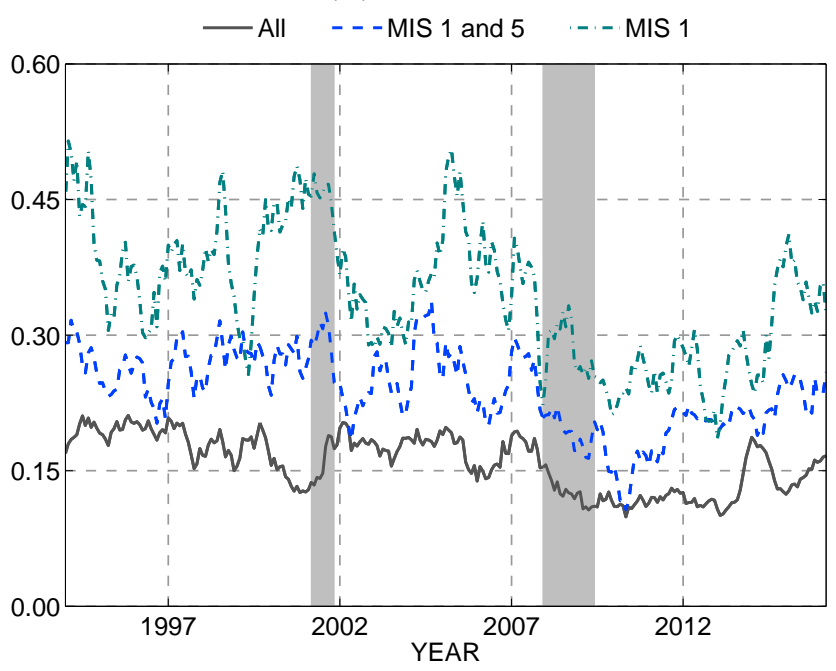

Figure B1: Monthly transition probabilities into multiple jobholding NOTE: MA-smoothed time series cleared from seasonal variations, margin error and timeaggregation bias. Gray-shaded areas indicate NBER recession periods. 
(a) $\mathrm{M} \rightarrow \mathrm{F}_{\mathrm{S}}$

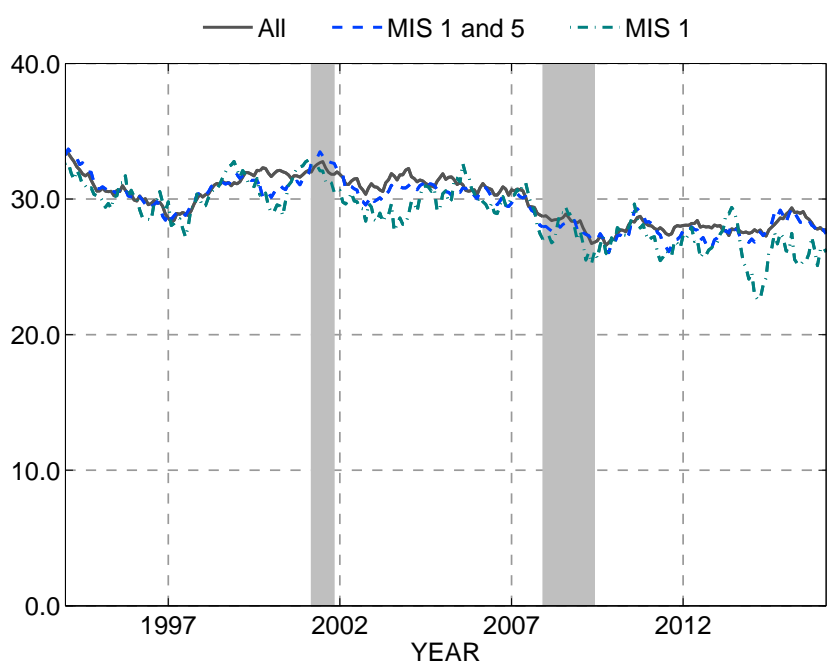

(b) $\mathrm{M} \rightarrow \mathrm{P}_{\mathrm{S}}$

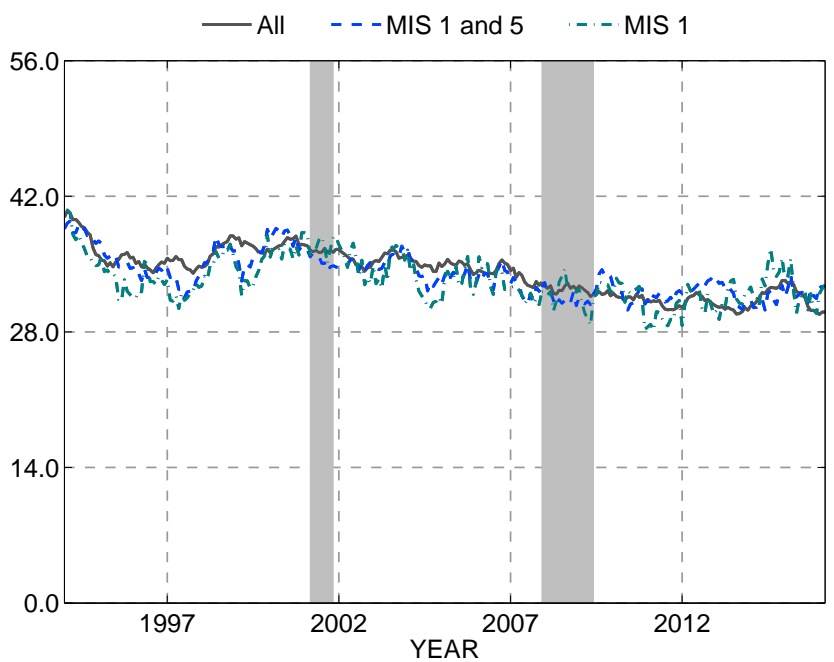

(c) $\mathrm{M} \rightarrow \mathrm{N}$

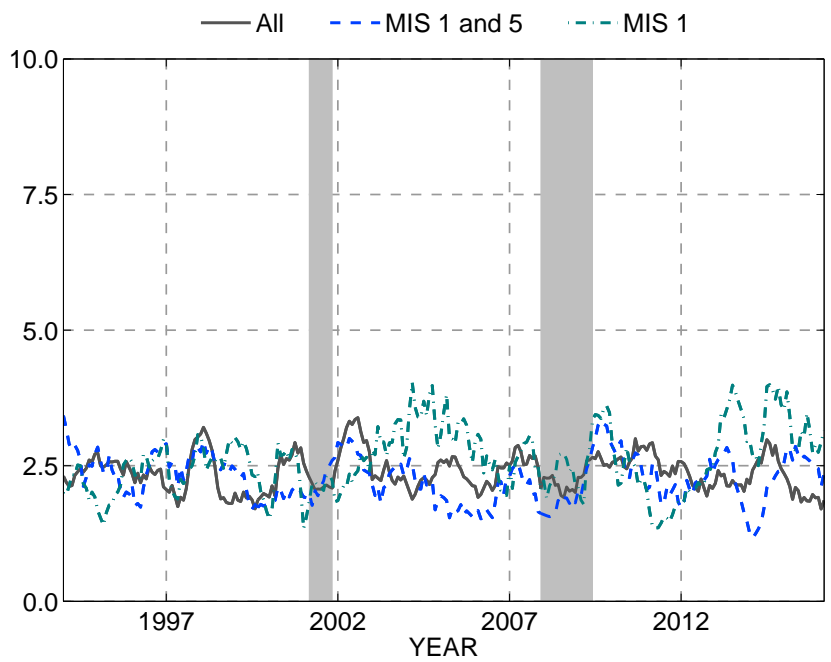

Figure B2: Monthly transition probabilities out of multiple jobholding NOTE: MA-smoothed time series cleared from seasonal variations, margin error and timeaggregation bias. Gray-shaded areas indicate NBER recession periods. 
tematically higher in the MIS1 and MIS5 samples. This is not unexpected: if CPS respondents underreport second jobs during the subsequent rounds of interview, then it becomes less likely to observe a transition into multiple jobholding in these data. For reasons we cannot fathom, on the other hand rotation group bias has no impact on the probabilities to leave multiple jobholding reported in Figure B2. Finally, it is clear in Figures B1 and B2 that the transition probabilities are less precisely estimated when we use these smaller samples.

To check the robustness of the results, we repeat the variance decomposition exercise with data from the MIS1 and MIS5 samples. The reason we do not use the MIS1 sample alone is that our focus is on the long-run evolution of multiple jobholding; as just discussed, in the MIS1 sample there is large amount of short-run variability that is irrelevant for our purpose.

Table B2: Variance decomposition of the multiple jobholding rate: MIS 1 and 5 samples

\begin{tabular}{|c|c|c|c|}
\hline \multicolumn{2}{|l|}{$\begin{array}{c}\text { Inflows } \\
(1)\end{array}$} & \multicolumn{2}{|l|}{$\begin{array}{c}\text { Outflows } \\
(2)\end{array}$} \\
\hline$\beta\left(F_{S} \rightarrow M\right)$ & 72.3 & $\beta\left(F_{M} \rightarrow S\right)$ & 6.8 \\
\hline$\beta\left(P_{S} \rightarrow M\right)$ & 21.5 & $\beta\left(P_{M} \rightarrow S\right)$ & -4.5 \\
\hline$\beta(N \rightarrow M)$ & 2.5 & $\beta(M \rightarrow N)$ & 0.5 \\
\hline$\sum_{i \neq M} \beta(i \rightarrow M)$ & 96.4 & $\sum_{j \neq M} \beta(M \rightarrow j)$ & 2.8 \\
\hline
\end{tabular}

NOTE: The entries in column 1 (resp. 2) show the variance contribution in percent of the inflows (resp. outflows) to the evolution of the multiple jobholding rate.

Table B2 reports the results. In line with the discussion of Section 4, we find that the inflows remain the predominant force that shapes the evolution of multiple jobholding. In particular, the variance contribution of transitions from holding a single full-time job are still very large, at 72.3 percent. One difference with Section 4 is that the so-called 'stock-flow fallacy' is less severe: the inflows do not overpredict changes in the multiple jobholding rate. Finally, the fit of the variance decomposition remains high: the sum of the $\beta$ coefficients shows that its explains 99.2 percent of the variations. We conclude that the results are robust to rotation group bias.

\section{B.3 Subgroup results}

Figures B3 and B4 compare the baseline transition probabilities (solid lines) among male workers with the estimates for some subgroups of this population (dashed lines). The corresponding plots for female workers are provided in Figures B5 and B6. These figures allow to gauge the sensitivity of the trends to various sample restrictions. We think that, in addition, the subgroups that we select are interesting in their own rights because of differences in their multiple jobholding rate (details follow). Since our empirical protocol delivers accurate estimates of the transition probabilities, it is worth applying it to construct data for these subgroups.

The leftmost graphs in Figures B3 to B6 report the transition probabilities for prime-age workers (i.e. individuals aged 25 to 54). The multiple jobholding rate is actually similar across young, prime-age and older workers (cf. Table 1). Meanwhile, the decrease in multiple 
(a) $\mathrm{F}_{\mathrm{S}} \rightarrow \mathrm{M}$
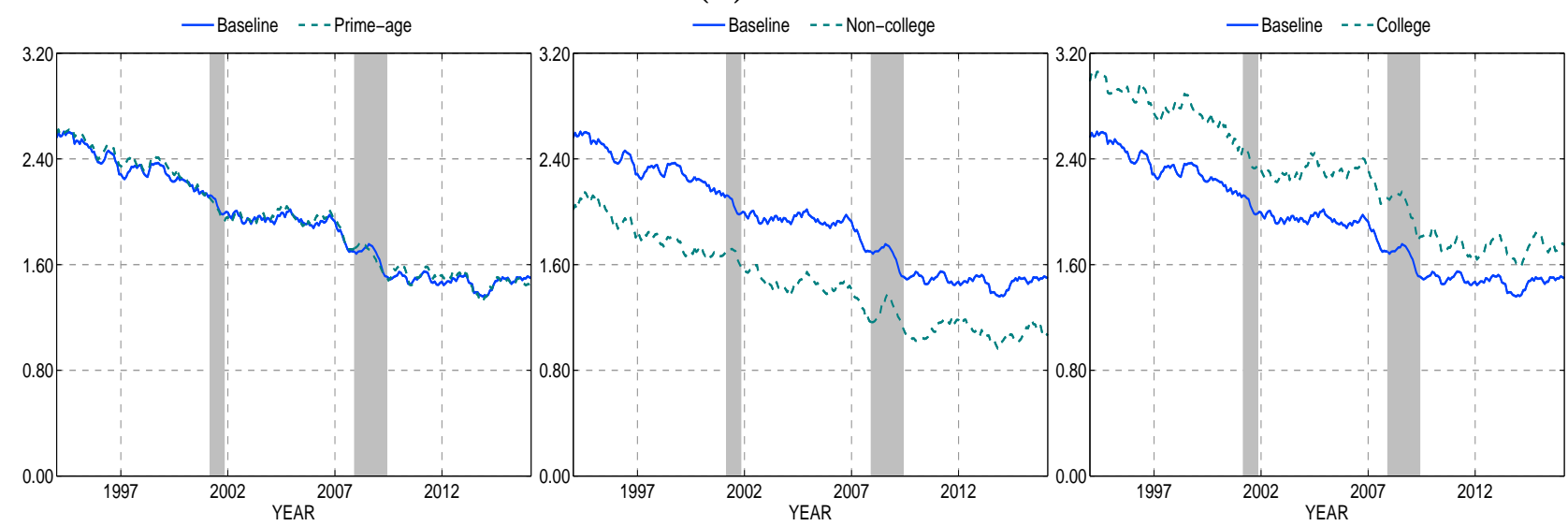

(b) $\mathrm{P}_{\mathrm{S}} \rightarrow \mathrm{M}$

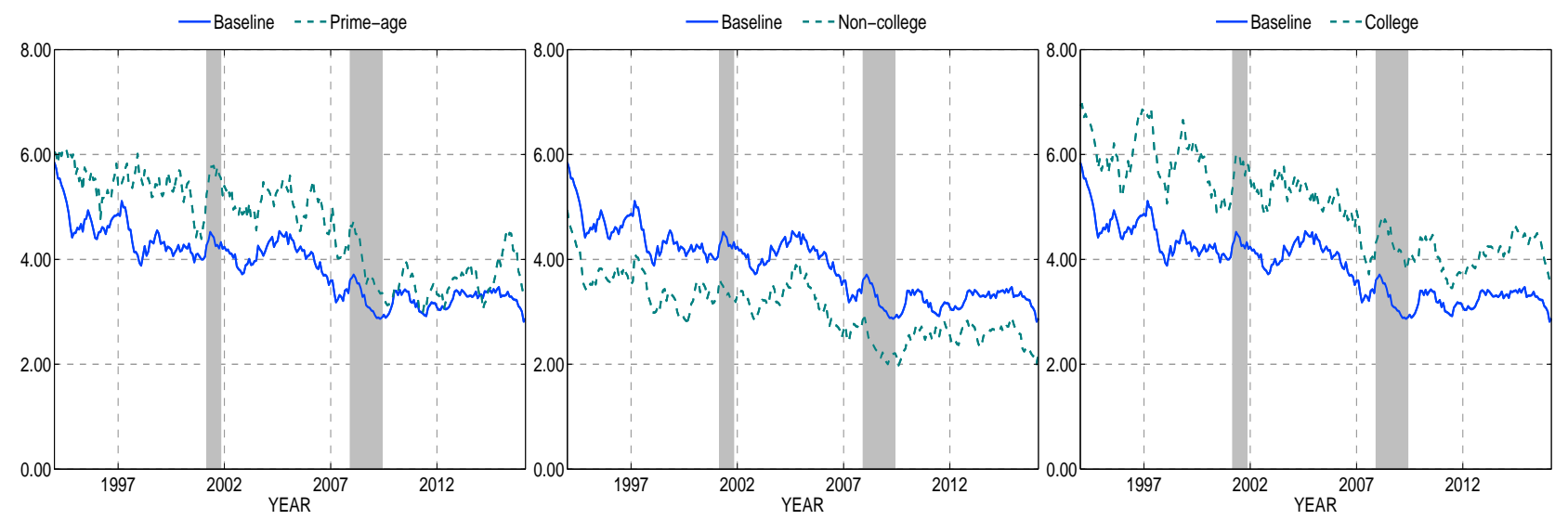

(c) $\mathrm{N} \rightarrow \mathrm{M}$

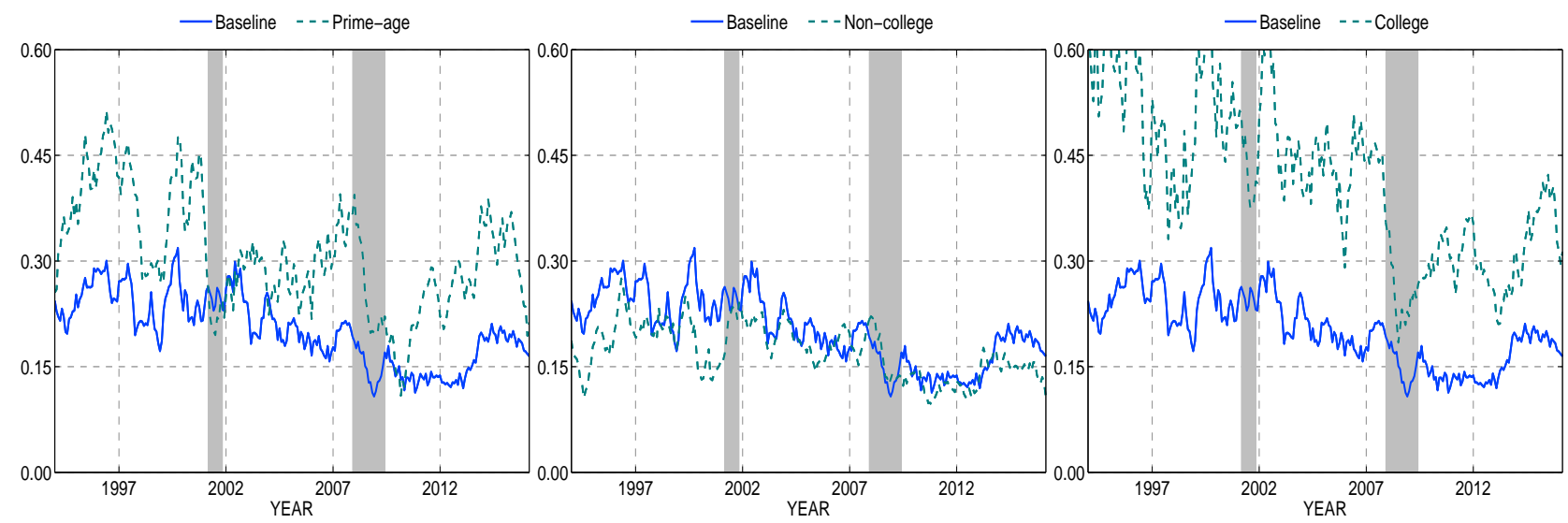

Figure B3: Monthly transition probabilities into multiple jobholding: Men NOTE: MA-smoothed time series cleared from seasonal variations, margin error and timeaggregation bias. Gray-shaded areas indicate NBER recession periods. 
(a) $\mathrm{M} \rightarrow \mathrm{F}_{\mathrm{S}}$
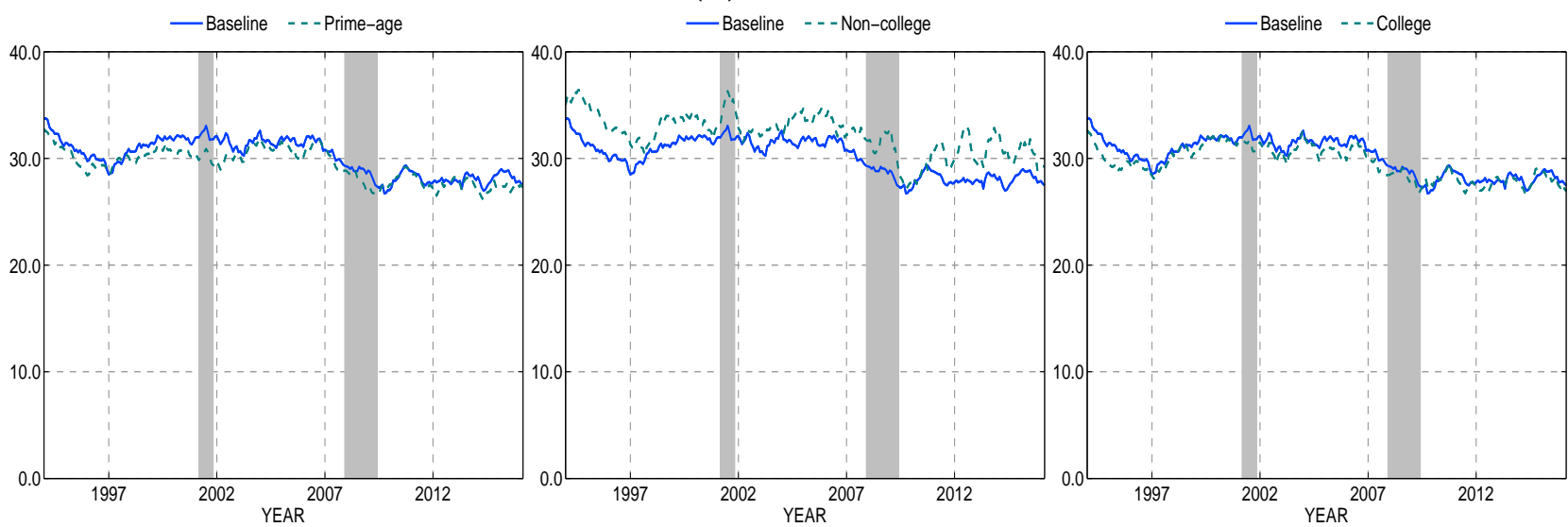

(b) $\mathrm{M} \rightarrow \mathrm{P}_{\mathrm{S}}$
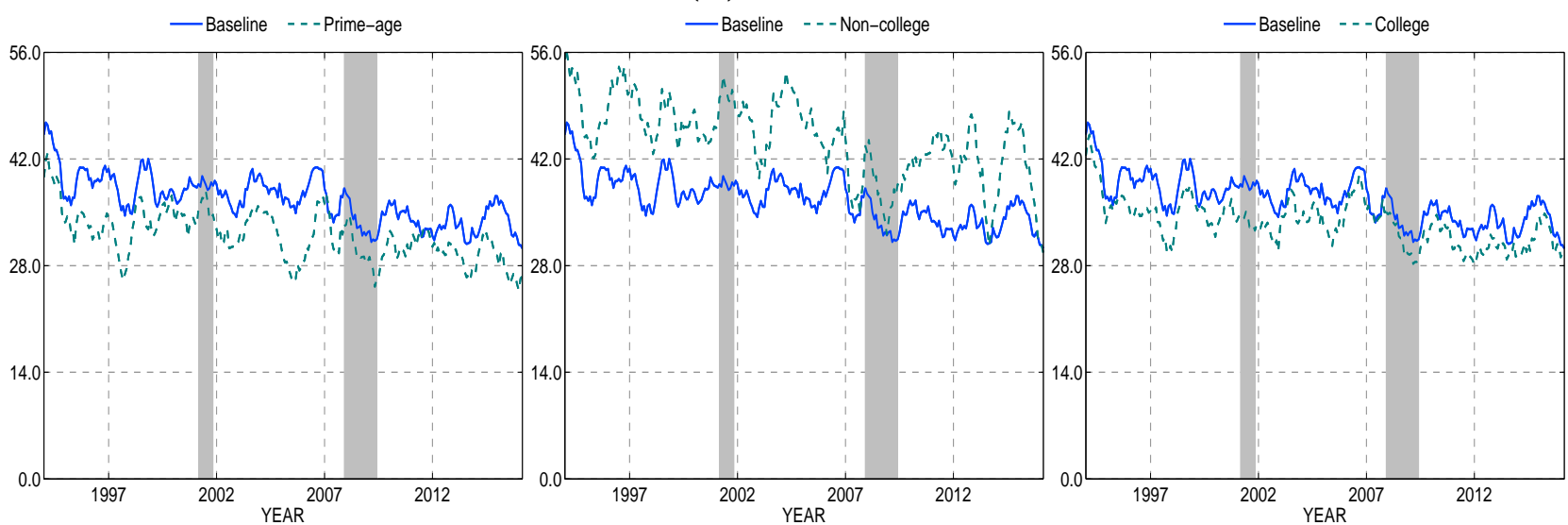

(c) $\mathrm{M} \rightarrow \mathrm{N}$
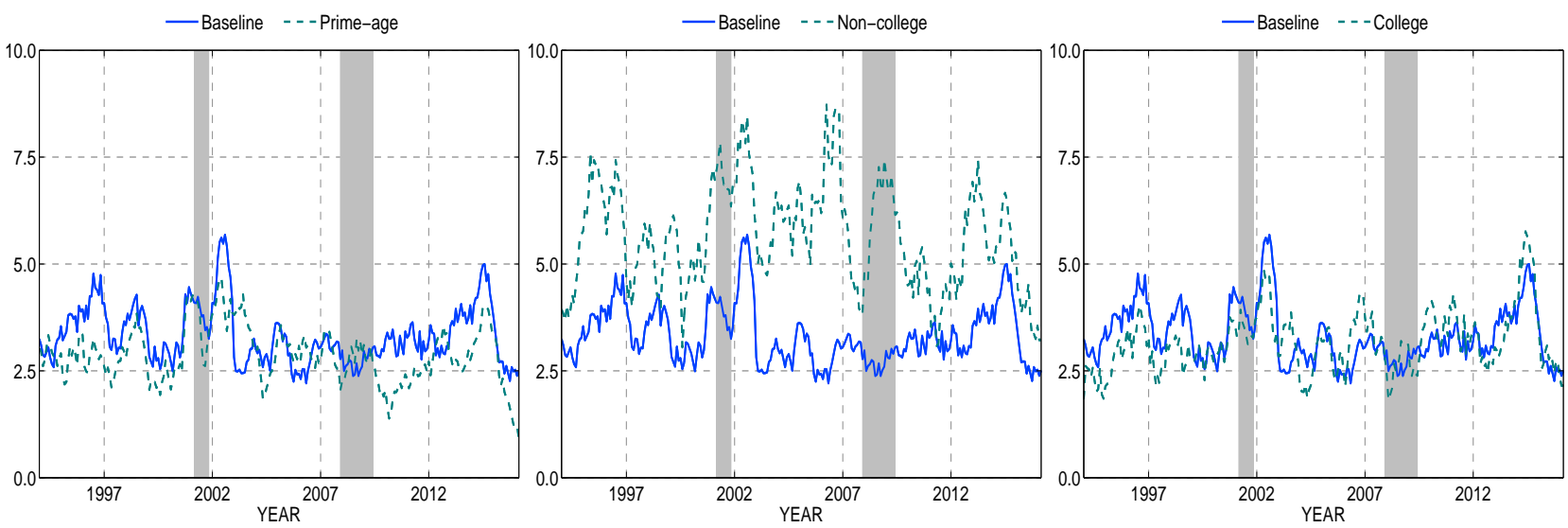

Figure B4: Monthly transition probabilities out of multiple jobholding: Men NOTE: MA-smoothed time series cleared from seasonal variations, margin error and timeaggregation bias. Gray-shaded areas indicate NBER recession periods. 
(a) $\mathrm{F}_{\mathrm{S}} \rightarrow \mathrm{M}$
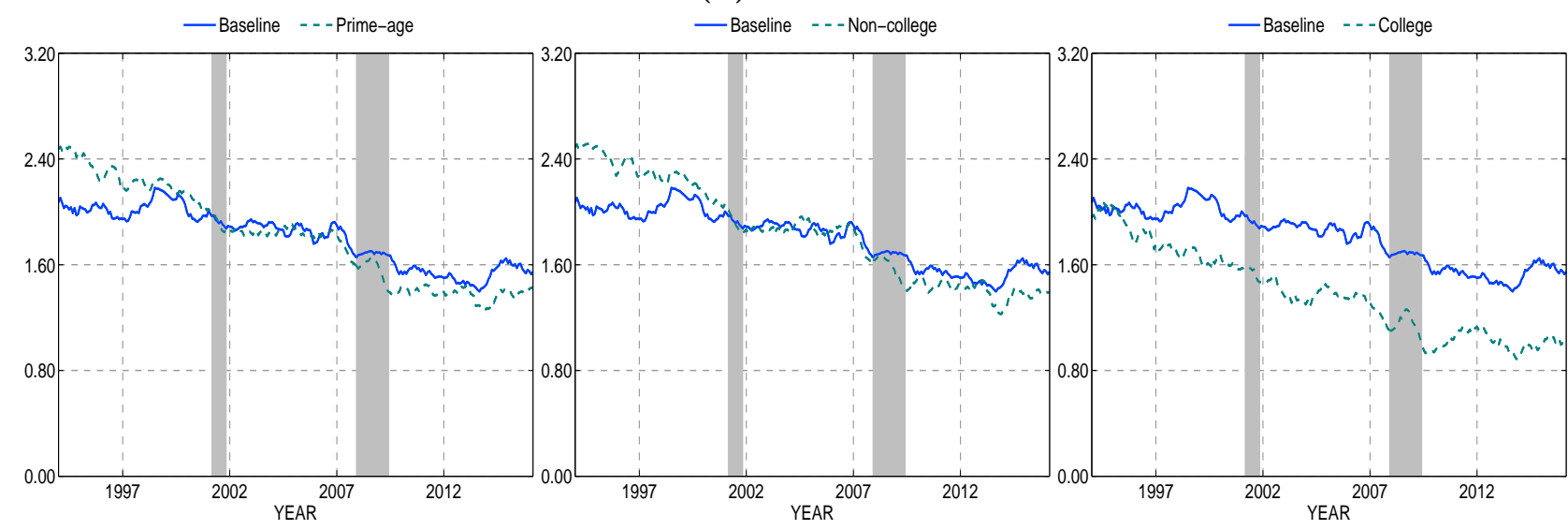

(b) $\mathrm{P}_{\mathrm{S}} \rightarrow \mathrm{M}$
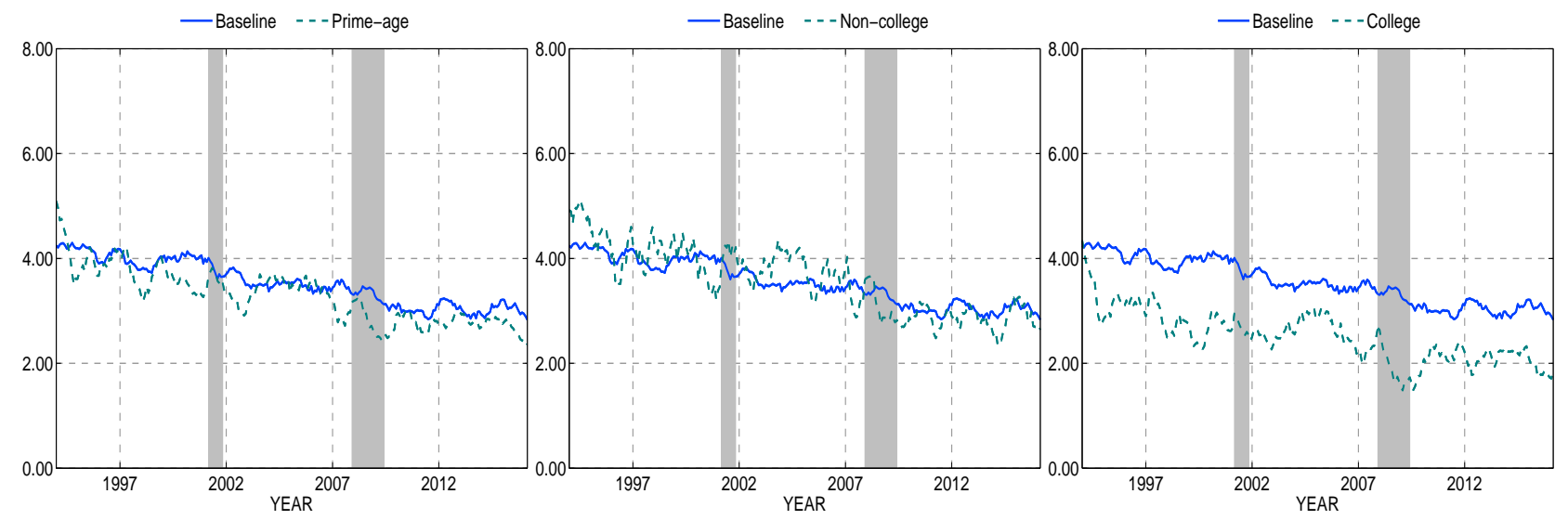

(c) $\mathrm{N} \rightarrow \mathrm{M}$

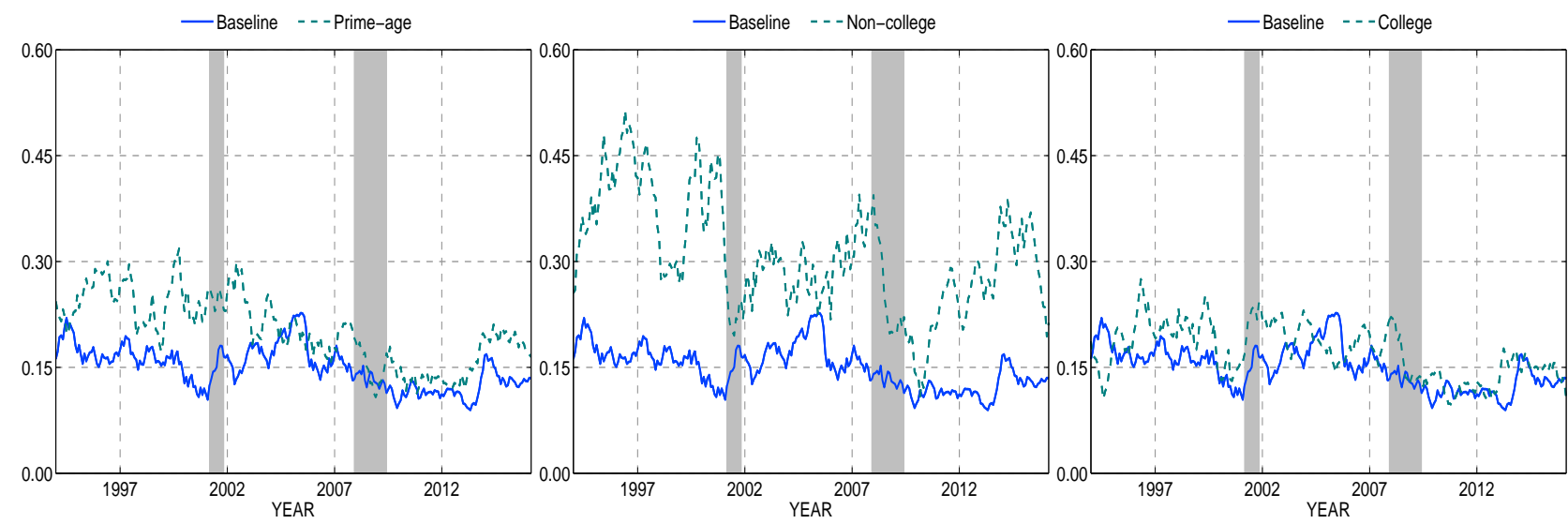

Figure B5: Monthly transition probabilities into multiple jobholding: Women NOTE: MA-smoothed time series cleared from seasonal variations, margin error and timeaggregation bias. Gray-shaded areas indicate NBER recession periods. 
(a) $\mathrm{M} \rightarrow \mathrm{F}_{\mathrm{S}}$
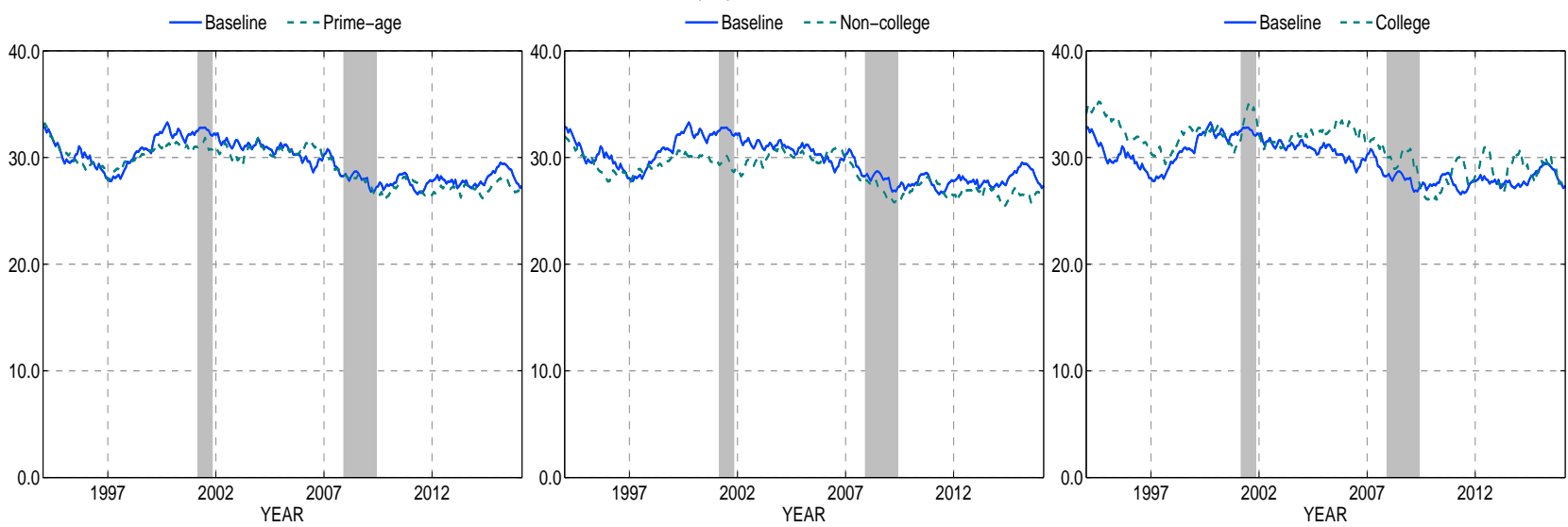

(b) $\mathrm{M} \rightarrow \mathrm{P}_{\mathrm{S}}$
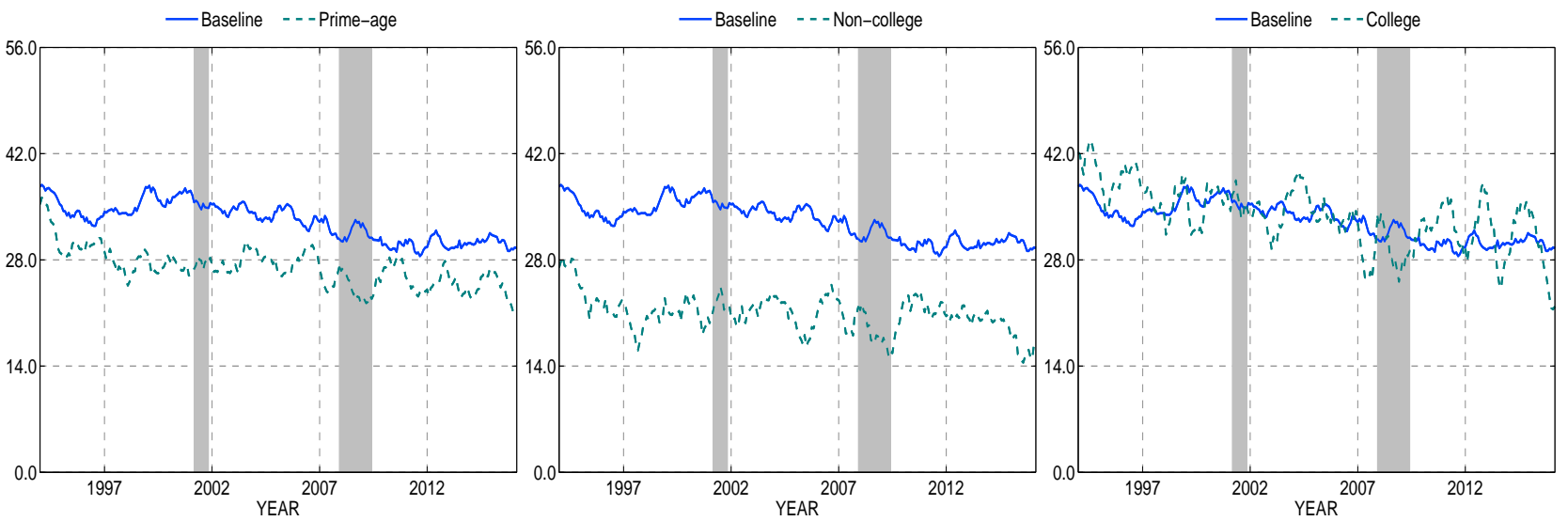

(c) $\mathrm{M} \rightarrow \mathrm{N}$
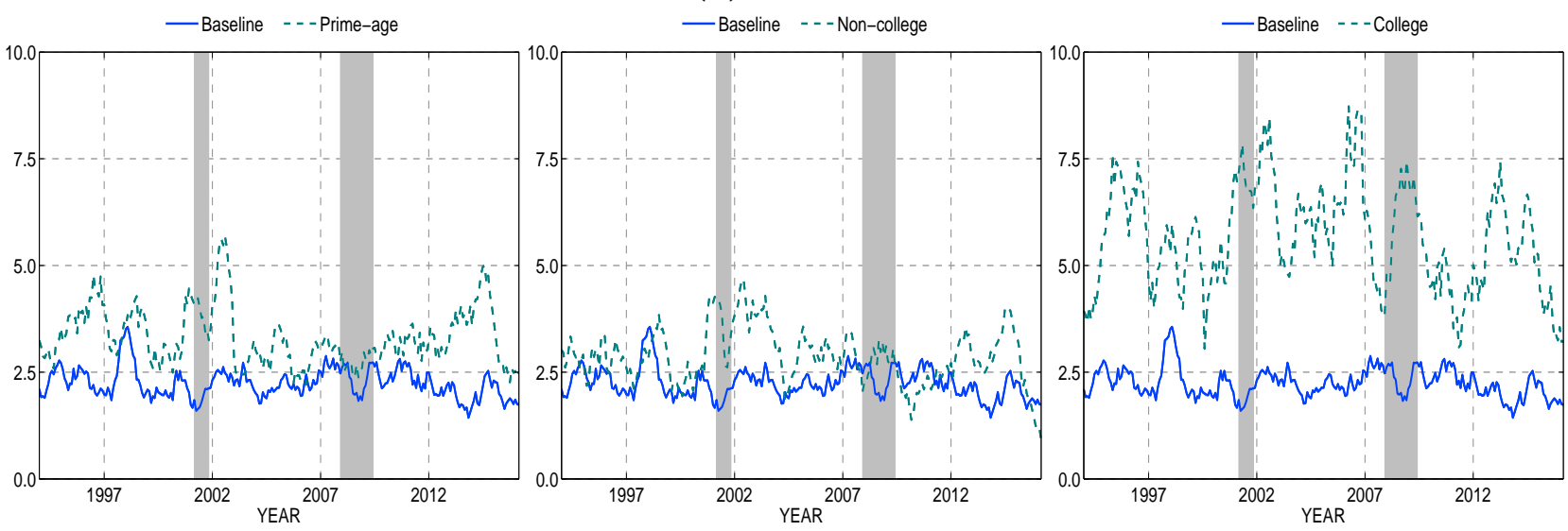

Figure B6: Monthly transition probabilities out of multiple jobholding: Women NOTE: MA-smoothed time series cleared from seasonal variations, margin error and timeaggregation bias. Gray-shaded areas indicate NBER recession periods. 
jobholding over the sample period is much more pronounced among prime-age individuals. A closer look at the data shows that the time series of transition probabilities are rather flat for workers aged 55 to 64 . The differences in the trend between prime-age and younger workers, on the other hand, are mostly driven by the prevalence of part-time work among younger workers.

The graphs in the middle and the rightmost graphs of Figures B3 to B6 display the transition probabilities of non-college and college workers, respectively. We emphasize this partition of the working-age population because it maximizes heterogeneity with respect to the rates of multiple jobholding. The different plots show that multiple jobholding is more prevalent among workers with higher educational attainment because they are more likely to take on a second job during single jobholding. The probability of transitions in the opposite direction is less dissimilar between less-educated and more-educated groups. Finally, we note that the trends in transition probabilities for men are not driven by the choice of the sample. For women, on the other hand, we observe different dynamics in the probability of moving from single jobholding to multiple jobholding (panels a and b Figure B3). These changes may be driven by a change in women's selection into full-time and part-time single jobholding. 